\title{
Glycan labeling strategies and their use in identification and quantification
}

\author{
L. R. Ruhaak • G. Zauner • C. Huhn • C. Bruggink • \\ A. M. Deelder • M. Wuhrer
}

Received: 18 November 2009/Revised: 22 January 2010 / Accepted: 22 January 2010/Published online: 12 March 2010

(C) The Author(s) 2010. This article is published with open access at Springerlink.com

\begin{abstract}
Most methods for the analysis of oligosaccharides from biological sources require a glycan derivatization step: glycans may be derivatized to introduce a chromophore or fluorophore, facilitating detection after chromatographic or electrophoretic separation. Derivatization can also be applied to link charged or hydrophobic groups at the reducing end to enhance glycan separation and mass-spectrometric detection. Moreover, derivatization steps such as permethylation aim at stabilizing sialic acid residues, enhancing massspectrometric sensitivity, and supporting detailed structural characterization by (tandem) mass spectrometry. Finally, many glycan labels serve as a linker for oligosaccharide attachment to surfaces or carrier proteins, thereby allowing interaction studies with carbohydrate-binding proteins. In this review, various aspects of glycan labeling, separation, and detection strategies are discussed.
\end{abstract}

Keywords Capillary electrophoresis · Carbohydrate .

Derivatization $\cdot$ Liquid chromatography

Mass spectrometry $\cdot$ Review

$\begin{array}{ll}\text { Abbreviations } \\ \text { 2-AA } & \text { 2-aminobenzoic acid } \\ \text { 2-AB } & \text { 2-aminobenzamide } \\ \text { ANTS } & \text { 2-aminonaphthalene trisulfonic acid } \\ \text { APTS } & \text { 1-aminopyrene-3,6,8-trisulfonic acid } \\ \text { BACH } & \text { 6-(biotinyl)-aminocaproyl hydrazide } \\ \text { BGE } & \text { background electrolyte } \\ \text { BNAH } & \text { biotinyl-L-3-(2-naphthyl)-alanine hydrazide }\end{array}$

L. R. Ruhaak · G. Zauner · C. Huhn · C. Bruggink •

A. M. Deelder $\cdot$ M. Wuhrer $(\bowtie)$

Biomolecular Mass Spectrometry Unit,

Department of Parasitology, Leiden University Medical Center,

P.O. Box 9600, 2300RC Leiden, The Netherlands

e-mail: m.wuhrer@lumc.nl

\begin{tabular}{|c|c|}
\hline $\mathrm{BOC}$ & tert-butoxycarbonyl \\
\hline $\mathrm{CBP}$ & carbohydrate-binding protein \\
\hline $\mathrm{CE}$ & capillary electrophoresis \\
\hline CGE & capillary gel electrophoresis \\
\hline CID & collision-induced dissociation \\
\hline DHB & 2,5-dihydroxybenzoic acid \\
\hline ESI & electrospray ionization \\
\hline GU & glucose unit \\
\hline HILIC & hydrophilic interaction liquid chromatography \\
\hline HPAEC & high-pH anion-exchange chromatography \\
\hline HPLC & high-performance liquid chromatography \\
\hline LC & liquid chromatography \\
\hline MALDI & matrix-assisted laser desorption/ionization \\
\hline MEKC & micellar electrokinetic chromatography \\
\hline PA & 2-aminopyridine \\
\hline PAD & pulsed amperometric detection \\
\hline PGC & porous graphitized carbon \\
\hline PMP & 1-phenyl-3-methyl-5-pyrazolone \\
\hline $\mathrm{RP}$ & reverse phase \\
\hline RSD & relative standard deviation \\
\hline SPE & solid-phase extraction \\
\hline TOF & time of flight \\
\hline
\end{tabular}

\section{Introduction}

Glycan analysis is increasingly applied in biological research, clinical analysis, and pharmaceutical biotechnological production. Specific glycosylation patterns have been associated with states of health and disease [1-4]. Moreover, glycosylation changes may modulate the biological activity of proteins, as demonstrated, for example, for the glycosylation of the Fc moiety of recombinant immunoglobulin $\mathrm{G}[5,6]$. 
Many approaches for analysis of oligosaccharides from glycoproteins have been described [7-9], and strategies for the analysis of the glycosylation of immunoglobulin $G$ (both natural and recombinant) have recently been summarized [10]. A large number of methods focus on the analysis of released and subsequently derivatized glycans. These approaches allow in-depth analysis of the oligosaccharide structure independent of the carrier glycoprotein, but provide no information on the attachment site of the glycan. As the application of separation methods with optical or massspectrometric detection for the characterization of glycans is hindered by the lack of a chromophore and their poor ionization properties, a wide variety of derivatization strategies with a large number of different labels have been applied.

In this review an overview of the techniques applicable for glycan derivatization is given, e.g., reductive amination, Michael addition, hydrazide labeling, and permethylation, followed by some aspects on purification of derivatized glycans. Additionally, strategies for the analysis of tagged oligosaccharides using chromatographic and electromigrative separation techniques as well as mass spectrometry (MS) and their use in quantitation will be addressed. Criteria for the choice of derivatization strategies and detection methods will be discussed.

\section{Derivatization strategies}

A large number of glycan derivatization strategies have been described in the literature. The most common reaction employed is the reductive amination. Permethylation is also often applied. Alternatively, Michael addition or hydrazide labeling may be applied. Various compounds which provide the required functional group for the labeling reaction can be used. The application of a specific release method may restrict the labeling options. Reductive amination, Michael addition, and hydrazide labeling all require the reducing end of the glycan, which is not present on $O$-glycans released by reductive $\beta$-elimination. Labeling reagents are usually present in large excess, and most of the analytical techniques require a sample workup to remove excess labeling reagents. Most frequently, size-exclusion chromatography and solid-phase extraction (SPE) are applied.

\section{Release methods}

An efficient, reliable method for the release of oligosaccharides from protein or peptide backbones is a prerequisite for their detection [7]. Several methods for $\mathrm{N}$-glycan or $O$ glycan release have been reported, and are represented in Fig. 1 [7-19].

$\mathrm{N}$-Glycans are commonly released enzymatically using PNGase F or A (see Fig. 1). The hydrazinolysis approach is applicable for $N$-glycans as well as $O$-glycans [7, 18, 19], yielding glycans with a free reducing terminus. Even though the reaction mechanism of hydrazinolysis is not fully understood, it is generally accepted that glycan release occurs via an initial $\beta$-elimination step prior to a reaction with hydrazine resulting in a hydrazone derivate [19]. The method has some major drawbacks, such as the necessity to use anhydrous hydrazine, which is a highly toxic and explosive chemical also used in rocket fuel [20]. Several other disadvantages of the hydrazinolysis method have been given by various groups: one example is the release of $O$ glycans by hydrazinolysis, which has to be followed by re$\mathrm{N}$-acetylation and a concomitant acetohydrazone cleavage
Fig. 1 Strategies for $N$-glycan and $O$-glycan release from glycoproteins and glycopeptides

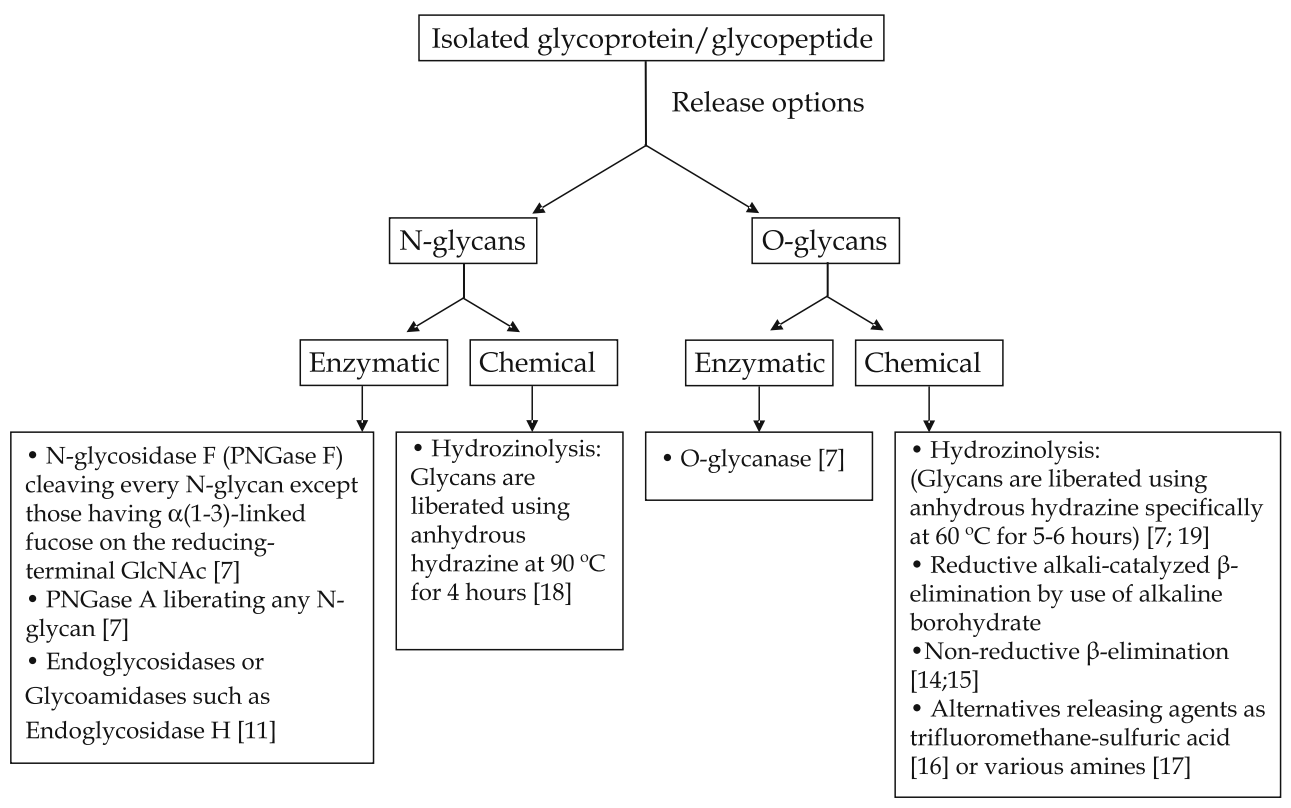


step, which is crucial in order to obtain intact glycans with a free reducing terminus [7, 9, 18-23].

Enzymatic release of $O$-glycans has a much more limited use owing to the very narrow substrate specificity of the enzymes available. Only two $O$-glycanases are commercially available [7], the use of which is unfortunately restricted to the liberation of the unsubstituted core 1 disaccharide Gal $\beta 1-3 \mathrm{GalNac} \alpha$ linked to either serine or threonine. Accordingly, chemical release is the major method for O-linked oligosaccharide liberation and several options have been reported (see Fig. 1), all of which, however, have the inherent risk that a possible, unwanted degradation step called a "peeling" reaction can occur [19]. Peeling refers to a base-catalyzed elimination reaction which results in the loss of the 3 -substituent of the innermost residue of an oligosaccharide [19].

\section{Reductive amination}

\section{Reaction}

Glycans can be labeled at their reducing end using reductive amination. In this reaction, a label containing a primary amine group reacts in a condensation reaction with the aldehyde group of the glycan, resulting in an imine or Schiff base, which is reduced by a reducing agent to yield a secondary amine (see Fig. 2a). The reaction is often performed in dimethyl sulfoxide containing acetic acid [24], but alternative approaches using tetrahydrofuran [25] and methanol [26] have been described. An advantage of this labeling approach is the stoichiometric attachment of one label per glycan, allowing a direct quantitation based on fluorescence or UV-absorbance intensity.

\section{Labels}

Various labels have been used for the reductive amination of glycans. In two reviews, an extensive, though not complete list of labels for reductive amination has been given [27, 28]. The most widely applied labels are 2aminobenzamide (2-AB), 2-aminobenzoic acid (2-AA), 2aminopyridine (PA), 2-aminonaphthalene trisulfonic acid (ANTS), and 1-aminopyrene-3,6,8-trisulfonic acid (APTS). Labeling kits are available for the tags 2-AB, 2-AA, and PA (see, e.g., http://www.ludger.com) as well as for labeling with APTS (see http://www.beckmancoulter.com) and ANTS (see http://www.prozyme.com). 2-AB is a label that lacks negative charges and is widely applied in chromatographic analysis. An extensive database has been developed which uses the standardized elution positions of 2-ABlabeled glycans in hydrophilic interaction liquid chromatography (HILIC) with fluorescence detection for structural assignment [29]. PA is also widely used in high perfor- mance liquid chromatography (HPLC) profiling [30, 31], and databases for structural assignments based on standardized elution positions have been developed as well [32]. A major drawback of PA is the necessary recrystallization step prior to its use, since the commercially available compound lacks sufficient purity. The 2-AA label carries one negative charge, which makes it very versatile. It is used in HPLC and capillary electrophoresis (CE) separations as well as in positive-mode and negative-mode matrix-assisted laser desorption/ionization (MALDI) analysis, allowing detection of both neutral and sialylated glycan species [33-36]. APTS has three negative charges and is therefore very suitable for CE and capillary gel electrophoresis (CGE; see later) [37, 38]. However, the analysis of APTS-labeled oligosaccharides by MALDI appears to be difficult [39].

Other labels have been explored for their potential in quantitation: A [D $\left.\mathrm{D}_{4}\right] \mathrm{PA}$ label was introduced for glycosylation analysis [40]. Promising results were obtained; however, slight differences in retention times were observed between $\left[\mathrm{H}_{4}\right] \mathrm{PA}$ - and $\left[\mathrm{D}_{4}\right] \mathrm{PA}$-labeled glycans when they were separated on a $\mathrm{C}_{18}$ column. No other stationary phases have been tested [40].

In an alternative attempt, oligosaccharides from chondroitin sulfates were labeled with $\left[\mathrm{H}_{4}\right] 2-\mathrm{AA}$ or $\left[\mathrm{D}_{4}\right] 2-\mathrm{AA}$ $[41,42]$, and separation by size exclusion was performed to avoid possible shifts in retention time. A mass shift of only 4 Da was achieved, which may result in a partial overlap of glycan pair isotope envelopes in mass-spectrometric detection. Another option is to label oligosaccharides with $\left[{ }^{12} \mathrm{C}_{6}\right]$ alanine and $\left[{ }^{13} \mathrm{C}_{6}\right]$ alanine $[43,44]$. With use of this approach, a difference of $6 \mathrm{Da}$ is generated between the two different glycans, which is sufficient to have full resolution of the isotopic patterns of glycan pairs in MS. Moreover, the use of deuterium is avoided, so no retention shifts on $\mathrm{C}_{18}$ columns are observed.

\section{Reducing agent}

The most widely applied reducing agent is sodium cyanoborohydride. Very high yields of labeled oligosaccharides have been reported using this compound [24]. Alternatively, sodium triacetoxyborohydride [45] and borane-diethylamine [46] have been used; however, these compounds are not widely used within the glycoanalytical field.

As an alternative, we recently described the use of 2picoline borane for the reductive amination of oligosaccharides with 2-AA and 2-AB [47]. The use of sodium cyanoborohydride results in the release of the toxic compound hydrogen cyanide, 2-Picoline borane is an efficient, nontoxic alternative. When comparing the two compounds, we observed equal efficacies for reductive amination using various tags such as APTS (unpublished results), 2-AA, and 2-AB [47]. Moreover, 2-picoline borane 
Fig. 2 Labeling of glycans.

a 2-Aminobenzoic acid (2-AA) labeling via reductive amination,

b 1-phenyl-3-methyl-5-pyrazo-

lone labeling via a Michael-type

addition, c labeling with phe-

nylhydrazide, and $\mathbf{d}$ glycan

permethylation
A<smiles>Cc1ccc(C(=O)O)c(N)c1</smiles>

(Ib)

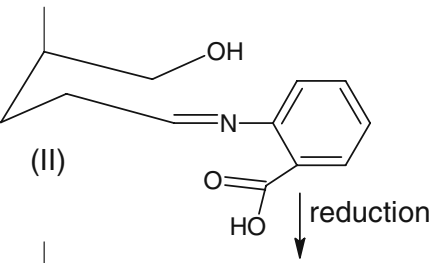

B

(Ib)<smiles>CC1CCC(O)COC1CC(=O)CO</smiles><smiles>Cc1cc(=O)n(-c2ccccc2)[nH]1</smiles>

C<smiles>CC1CCC(O)COC1CO</smiles>

(Ib)

D

(la)

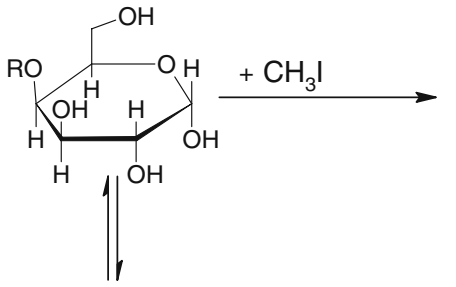

(II)

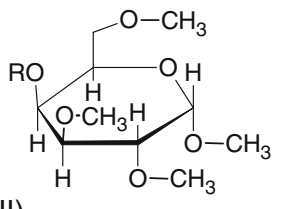

(Ib)

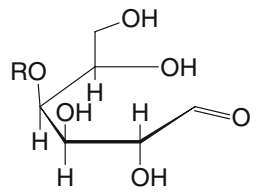

(II)<smiles></smiles>

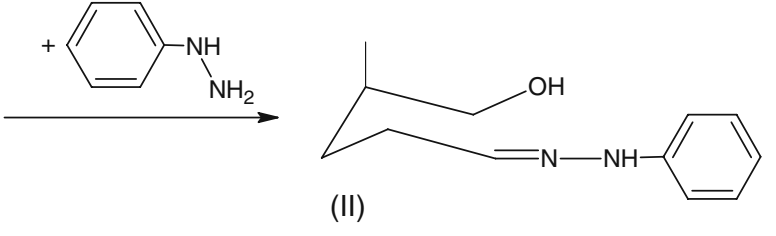

(II)<smiles>CC=C(O)C(O)=CC</smiles>

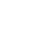


et al. [24] in 1995. The concentration of the labeling agent was recommended to be $0.25 \mathrm{M}$ or greater, whereas more than $1 \mathrm{M}$ reducing agent was required. The derivatization is enhanced by the addition of glacial acetic acid up to a content of $30 \%(\mathrm{v} / \mathrm{v})$. A reaction temperature of $60{ }^{\circ} \mathrm{C}$ was found to be optimal. With use of these conditions, all glycans are derivatized within $2 \mathrm{~h}$, and glycan degradation reactions such as acid-catalyzed loss of sialic acid are minimized. In a different study, the influence of different acids was evaluated for the derivatization of oligosaccharides with APTS [48]. Acids with lower $\mathrm{p} K_{\mathrm{a}}$ values, such as citric acid, malic acid, and malonic acid, were shown to result in higher yields than acetic acid when the derivatization was performed at $37^{\circ} \mathrm{C}$ for $16 \mathrm{~h}$. When higher temperatures and very acidic conditions are applied, partial degradation of the glycans will be induced with loss of sialic acids [49].

\section{Michael addition}

Labeling of the reducing end of glycans with reagents such as 1-phenyl-3-methyl-5-pyrazolone (PMP) by Michael addition is performed under alkaline conditions [50], thereby avoiding the considerable risk of loss of sialic acids under acidic conditions which is intrinsic to reductive amination reactions (see earlier).

The reaction itself is the nucleophilic addition of a carbanion to an $\alpha, \beta$-unsaturated carbonyl compound, and is one of the most useful methods for the mild formation of $\mathrm{C}-\mathrm{C}$ bonds. A detailed structural description of this glycan labeling procedure including the overall reaction scheme has been given by You et al. [50] and can also be found in a simplified version in Fig. 2b. Labeling reagents such as PMP $[51,52]$ or its methoxy analog 1-( $p$-methoxy)-phenyl3-methyl-5-pyrazolone are most often applied [53]. The derivatization reaction itself is a base-catalyzed Michaeltype addition involving a two step labeling process in which Michael donor molecules of the labeling reagent are formed and consecutively added to the reducing end of the glycan with a stoichiometry of two label molecules per glycan (II in Fig. 2b; [50]). After the addition of the first label molecule, a water molecule is lost [50], which results in the formation of an $\alpha, \beta$-unsaturated carbonyl compound. The following step yields a Michael 1,4-addition product by conjugation of the second label molecule. You et al. [50] introduced the novel labeling reagent 1-(2-naphthyl)-3methyl-5-pyrazolone for glycan labeling in the presence of an ammonium catalyst, which showed increased sensitivity in UV detection as well as a faster reaction time as compared with the previously applied PMP [50].

The use of the PMP label and related tags is restricted as no fluorescent labels have hitherto been reported. Moreover, as two label molecules are added per glycan, the chromatographic properties of the derivatized oligosaccharides are dominated by the tags, which may be disadvantageous in isomer separation.

\section{Hydrazide labeling}

Another labeling procedure can be accomplished by a reaction of glycans with labels providing a hydrazide end group (for the reaction mechanism, see Fig. 2c). Hydrazide labeling may be performed for mass-spectrometric detection [54] in combination with chromatography [55] or to allow biomolecular interaction analysis [56-59].

Lattova and Perreault [54] demonstrated that the conversion of monosaccharides and oligosaccharides to the corresponding phenylhydrazones is quantitative, meaning that no unreacted sugars were observed in the mass spectra after the labeling procedure [54]. In addition, it was shown that low picomolar sample concentrations were sufficient for structural identification by MALDI-MS and electrospray ionization (ESI) MS [55]. Carboxymethyl trimethylammonium hydrazide (Girard's T reagent) is a label which places a permanent positive charge at the reducing end of a glycan [60]. This label is suitable for sensitive analysis of glycans by MALDI time of flight (TOF) MS.

Shinohara et al. [58] were among the first to introduce hydrazide tagging of oligosaccharides for the introduction of a biotin tag, which allows further biomolecular interaction studies by immobilization of the glycan to streptavidincoated carriers [58]. Several applications of this approach, including the preparation of various hydrazide derivates followed [56, 57]. Leteux et al. [56] described the preparation of biotin hydrazide derivates of oligosaccharides employing biotinyl-L-3-(2-naphthyl)-alanine hydrazide (BNAH) and 6-(biotinyl)-aminocaproyl hydrazide (BACH) in which the ring of the reducing end monosaccharide is nonreduced. In this study BACH, BNAH, and 2-amino-(6amidobiotinyl)pyridine derivatives (the latter one being obtained under reductive amination conditions) were compared. The BNAH tag combines two advantageous features, i.e., the presence of a chromophore/fluorophore [similar to 2amino-(6-amidobiotinyl)pyridine] with the presence of an intact pyranose ring of the labeled glycan (similar to $\mathrm{BACH}$ derivates) [56]. A constitutive study by the same authors followed, where the same glycan tags conjugated to oligosaccharides on a streptavidin matrix were used to investigate their interaction with monoclonal antibodies, adhesion molecules, and E-, P-, and L-selectins [57].

(Per-)methylation

In permethylation, hydrogens on hydroxyl groups, amine groups, and carboxyl groups are replaced by methyl groups, yielding a hydrophobic sugar derivative (Fig. 2d) [61]. This 
is an advantageous derivatization step as it enhances the glycans' signal strength in MS with both ESI and MALDI [8]. Permethylation facilitates the spectral interpretation since both acidic and neutral structures can be measured in the positive ion mode [62] as the sialic acids are stabilized after the procedure [22]. Moreover, tandem MS of sodium adducts of permethylated glycans provides detailed information on linkage positions [63]. For structural characterization of glycans, permethylation is often preceded by reduction of the reducing end aldose with sodium borohydride to achieve an open-ring alditol, thereby providing a mass tag which facilitates spectral interpretation [63].

Ciucanu and Kerek [64] have introduced the basic permethylation protocol which has become a standard procedure and is applied in many cases for $O$-glycan as well as $\mathrm{N}$-glycan analysis with only minor alterations [50, 62, 63, 65-68]. Morelle and Michalski [22] provided a detailed step-by-step protocol and have summarized advantages and disadvantages of the procedure. Recently, Kang et al. [69] proposed packing a solid phase (either sodium hydroxide mesh beads or powder) in microspin columns or in fused-silica capillaries to allow effective and quantitative microscale derivatization of oligosaccharides in a short time [69]. The authors subsequently adapted this miniaturized approach to create a high-throughput method and combined it with an isotope labeling strategy [70, 71].

Recently, an elegant approach for sequential double permethylation for the analysis of sulfated glycans was introduced. Briefly, sulfated glycan samples are permethylated prior to the methanolytic cleavage of their sulfate groups. These oligosaccharides are then subjected to a second permethylation step using deuteromethyl iodide to label the hydroxyl groups resulting from methanolysis. By comparing the collision-induced dissociation (CID) $\mathrm{MS}^{2}$ spectra of permethylated and permethylated plus deuteromethylated samples, one can calculate the initial number of attached sulfate groups on the glycan. This method allows the detection and structural characterization of sulfated glycans using MS, avoiding the problem of signal suppression due to the presence of sulfate groups [72].

Alternative methylation protocols solely transform the carboxyl groups of monosaccharides such as sialic acids into methyl esters, thereby stabilizing sialic acid linkages for subsequent mass-spectrometric analysis [73].

\section{Strategies for purification}

After derivatization, labeled glycans often have to be purified prior to analysis. Not only does the excess of salts have to be removed (e.g., for MALDI analysis), but also the concentration of the labeling reagent, normally present in large excess during the labeling step, should be reduced.
Five major strategies are applied for this purpose: SPE [22, 29, 34, 74, 75], liquid-liquid extraction [64], gel filtration $[76,77]$, paper chromatography [23], and precipitation [75]. Typical examples of purification strategies are summarized in Table 1. SPE is mainly performed after reductive amination and hydrazide labeling [55], whereas liquidliquid extraction is the method of choice after permethylation [61, 64, 69] or Michael addition [51, 52, 78]. In permethylation procedures, liquid-liquid extraction may be followed by $\mathrm{C}_{18}$ SPE [79]. Paper chromatography may be used after reductive amination and hydrazide labeling [19, 80]. Precipitation with acetone is not widely applied, but may be used to remove proteins [75]. The strategies strongly differ in complexity as well as time consumption of sample handling. Among the five strategies, SPE is the method of choice for analyzing larger sample cohorts as it can be adapted to high-throughput setups [34]. The diversity of stationary phases for SPE is relatively large, and its use in purification of derivatized glycans is extensive. Several stationary phases have been used for purification of derivatized glycans by SPE: reverse phase (RP), porous graphitized carbon (PGC), HILIC, and anionexchange chromatography.

The introduction of hydrophobic properties by derivatization of native glycans (e.g., using the 2-AB label, see also later) is necessary for their adsorption to RP material, since nonderivatized glycans do not show sufficient retention on this material.

PGC is most widely and originally applied for nonderivatized glycans [81], but its use with labeled glycans has also been reported [82, 83]. Even though the mechanism is not well understood [84], the optimized method is highly specific for glycans. Elution is usually performed with acetonitrile/water mixtures containing trifluoroacetic acid (Table 1). The drawbacks of this method are the relatively high costs of the PGC and the fact that excess label may not be removed, depending on the properties of the label.

An upcoming approach for purification of mainly reductively aminated glycans is HILIC [29, 33, 34]. Several HILIC stationary phases have been described. In this approach, glycans are retained on the basis of their hydrophilic properties, whereas less hydrophilic excess label may be removed. We recently described the application of cellulose for purification of 2-AA-labeled glycans on a high-throughput platform [34]. Since elution of the derivatized glycans can be performed with water, samples can be stored immediately without the risk of the acidcatalyzed hydrolysis of sialic acids.

Glycan purification strategies may also include fractionation by anion-exchange chromatography of oligosaccharides labeled with PA or 2-AB, allowing the separation of neutral from sialylated glycans $[92,93]$. 
Table 1 Sample purification after glycan labeling

\begin{tabular}{|c|c|c|c|c|}
\hline Method & Material & Label & Comments & References \\
\hline SPE & $\mathrm{RP}, \mathrm{C}_{18}$ & RA, aniline & & {$[43]$} \\
\hline SPE & $\mathrm{RP}, \mathrm{C}_{18}$ & Permethylation & TFA may be added & {$[22,72,85]$} \\
\hline SPE & $\mathrm{RP}, \mathrm{C}_{18}$ & $\mathrm{HL}, \mathrm{BACH}$ & & {$[55]$} \\
\hline SPE & PGC & $\mathrm{RA}, 2-\mathrm{AB}$ & $\begin{array}{l}\text { Sample application in water, } \\
\text { elution using } 25 \%(\mathrm{v} / \mathrm{v}) \mathrm{ACN}\end{array}$ & {$[83]$} \\
\hline SPE & PGC & RA, benzylamine & $\begin{array}{l}\text { Sample application in water, elution } \\
\text { using } 20 \%(\mathrm{v} / \mathrm{v}) \mathrm{ACN}\end{array}$ & {$[82]$} \\
\hline SPE & $\begin{array}{l}\text { HILIC, nylon filter, } \\
\text { Oasis HLB or amide-2 }\end{array}$ & $\mathrm{RA}, 2-\mathrm{AA}$ & $\begin{array}{l}\text { Sample application in } 95 \% \mathrm{ACN} \text {, } \\
\text { elution using water }\end{array}$ & {$[33,86]$} \\
\hline SPE & HILIC, cellulose & RA, 2-AA & $\begin{array}{l}\text { Sample application in } 80 \% \mathrm{ACN} \text {, } \\
\text { elution using water }\end{array}$ & {$[34]$} \\
\hline SPE & HILIC, microelution plate & $\mathrm{RA}, 2-\mathrm{AB}$ & $\begin{array}{l}\text { Sample application in } 80 \% \mathrm{ACN} \text {, } \\
\text { elution using water }\end{array}$ & {$[29]$} \\
\hline SPE & HILIC, DPA-6S & RA, APTS & $\begin{array}{l}\text { Sample application in } 90 \% \mathrm{ACN} \text {, } \\
\text { elution using water }\end{array}$ & {$[87]$} \\
\hline Gel filtration & Sephadex G10 & RA, APTS & $\begin{array}{l}\text { Gel filtration in 96-well format in } \\
\text { filter plates }\end{array}$ & {$[38]$} \\
\hline Gel filtration & Toyopearl HW-40F & RA, APTS & & {$[88]$} \\
\hline Gel filtration & Sephadex G15 & RA, PA & & {$[89,90]$} \\
\hline Liquid-liquid extraction & Water/chloroform & Permethylation & $\begin{array}{l}\text { Permethylated glycans are in the organic } \\
\text { (lower) phase }\end{array}$ & {$[62,64,69,91]$} \\
\hline Liquid-liquid extraction & Water/dichloromethane & Permethylation & $\begin{array}{l}\text { Permethylated glycans are in the organic } \\
\text { (lower) phase }\end{array}$ & {$[61]$} \\
\hline Liquid-liquid extraction & Water/ethyl acetate & HL, phenylhydrazine & Labeled glycans are in the aqueous phase & {$[54]$} \\
\hline Liquid-liquid extraction & Water/butyl ether & MA, PMP & Labeled glycans are in the aqueous phase & {$[51]$} \\
\hline Liquid-liquid extraction & Water/chloroform & MA, PMP & Labeled glycans are in the aqueous phase & {$[52,78]$} \\
\hline Paper chromatography & $\begin{array}{l}3 \text { MM Whatman } \\
\text { filter paper }\end{array}$ & $\mathrm{RA}, 2-\mathrm{AB}, \mathrm{DAP}$ & Glycans are eluted using water & {$[19,80]$} \\
\hline Precipitation & Acetone & RA, PA & $\begin{array}{l}\text { Precipitation with water-free } \\
\text { acetone was conducted } 3 \text { times }\end{array}$ & {$[75]$} \\
\hline
\end{tabular}

$S P E$ solid-phase extraction, $R P$ reverse phase, $P G C$ porous graphitized carbon, HILIC hydrophilic interaction liquid chromatography, $R A$ reductive amination, $H L$ hydrazide labeling, $B A C H$ 6-(biotinyl)-aminocaproyl hydrazide, 2- $A B$ 2-aminobenzamide, 2- $A A$ 2-aminobenzoic acid, APTS 1-aminopyrene-3,6,8-trisulfonic acid, $P A$ 2-aminopyridine, $M A$ Michael addition, $P M P$ 1-phenyl-3-methyl-5-pyrazolone, DAP 2,6diaminopyridine, TFA trifluoroacetic acid, $A C N$ acetonitrile

\section{Separation and detection}

\section{Electromigrative separation techniques}

Electromigrative separation techniques are now frequently applied in glycan and carbohydrate analysis, providing high-speed separations and high resolution as has been summarized in a number of reviews [39, 94-101]. The separations are based on differences in the effective electrophoretic mobility of the analytes in the separation medium, when an external voltage is applied. Whereas "acidic" glycans carrying sialic acid, glucuronic acid, sulfate, or phosphate are negatively charged at low $\mathrm{pH}$ ( $\mathrm{p} K_{\mathrm{a}}$ of sialic acids is 2.0-2.8 [102]), "neutral" glycans will only exhibit partial negative charges at very high $\mathrm{pH}$ owing to the deprotonation of hydroxyl groups (see also "High-pH anion-exchange chromatography").
The electromigrative separation techniques applied so far include $\mathrm{CE}$, micellar electrokinetic chromatography (MEKC), gel electrophoresis (also called "fluorescenceassisted carbohydrate electrophoresis), CGE, and capillary electrochromatography (see Table 2). CE gives rise to a charge-based separation; therefore, sialoforms are relatively easy to separate with high resolution [34]. An interesting approach for the separation of APTS-labeled glycans was presented by Zhuang et al. [103]. The authors used chip technology and CE [background electrolyte (BGE) $1 \mathrm{mM}$ phosphate and $20 \mathrm{mM} N$-(2-hydroxyethyl)piperazine- $N$ 'ethanesulfonic acid at $\mathrm{pH}$ 6.8]. A very fast analysis (less than $3 \mathrm{~min}$ ) was possible with high resolution (see Fig. 3). Further separation based on the size and the shape of the glycans needs a more careful optimization of the BGE, but can be achieved by optimizing the $\mathrm{pH}$ and the concentration of organic modifiers in the BGE $[104,105]$. Alternatively, 


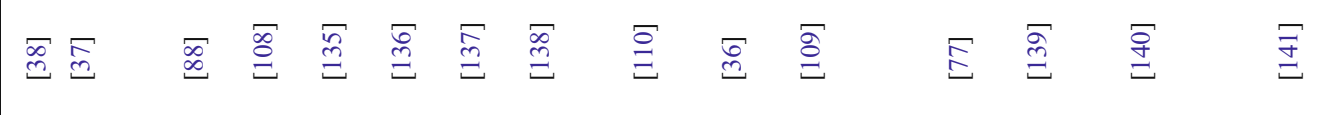

$$
\text { (1) }
$$$$
\text { ( }
$$

$$
\text { (1) }
$$

$$
\text { . }
$$

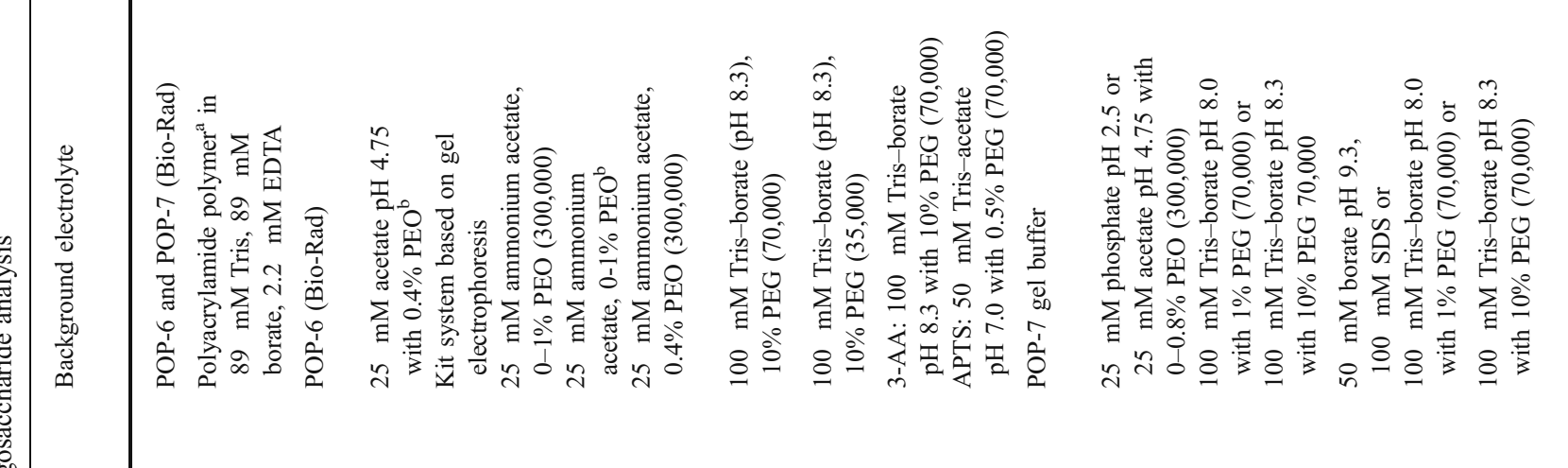

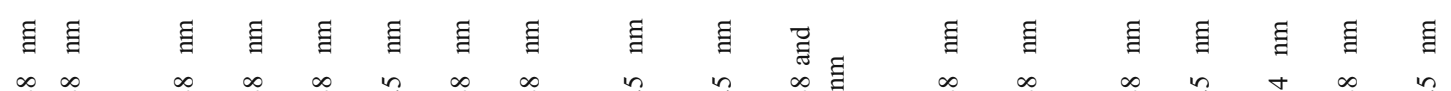

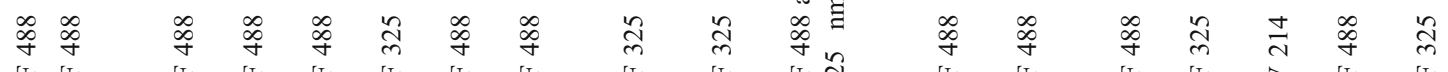

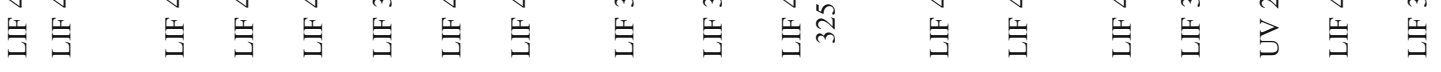

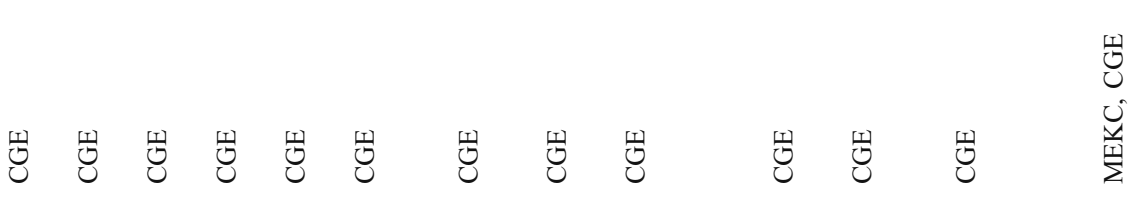

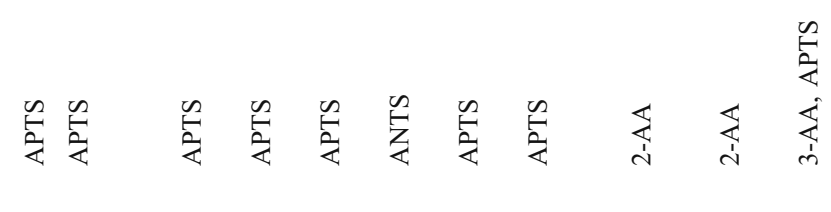

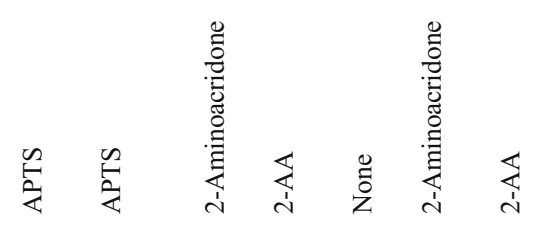

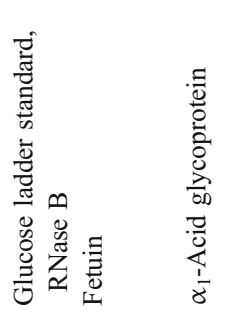<smiles>CC1[C@H](C)C[C@H]1C</smiles>

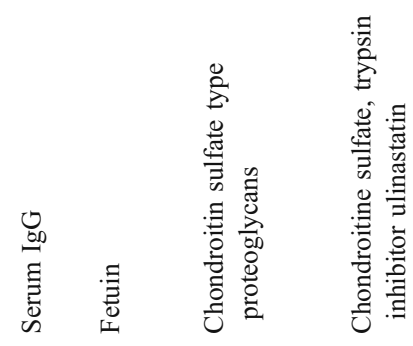




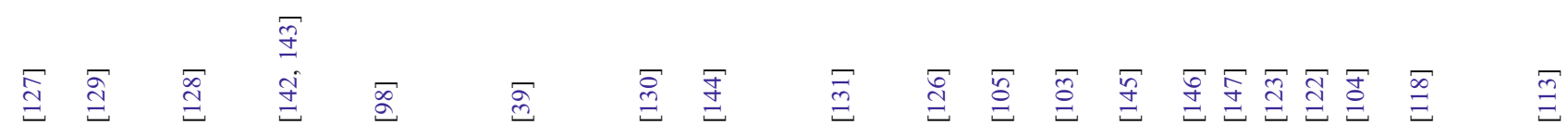
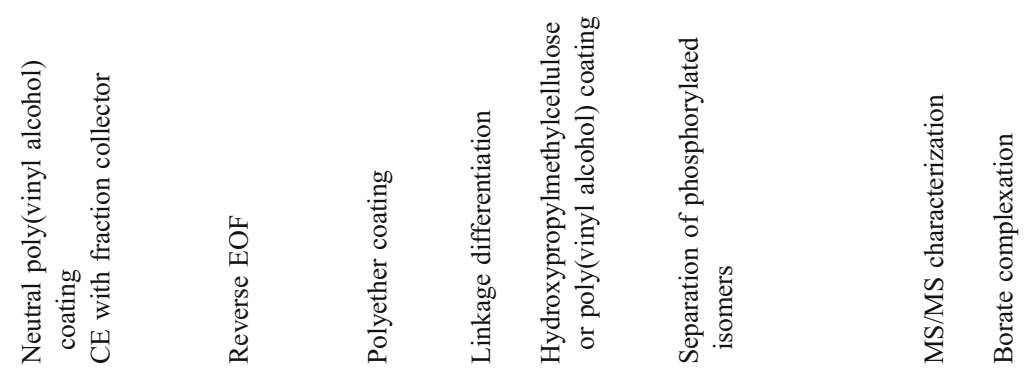

$\frac{\pi}{\frac{\pi}{0}}$

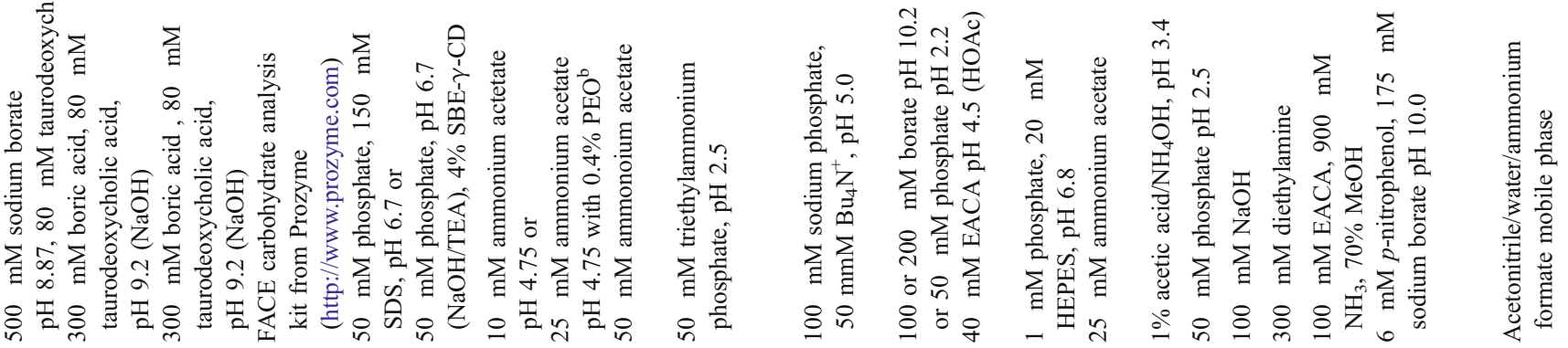

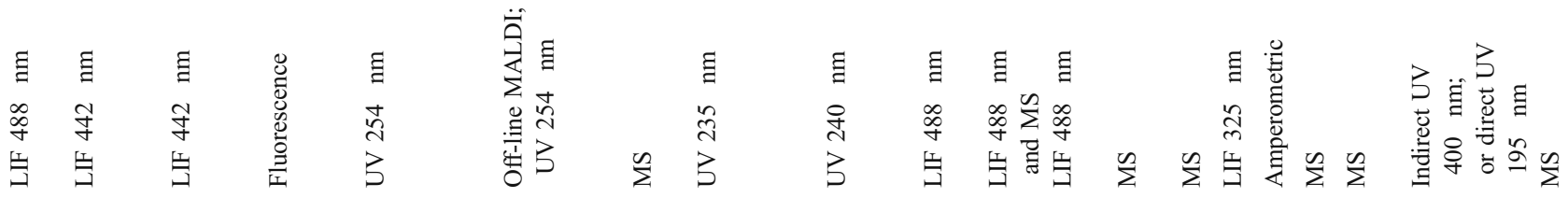

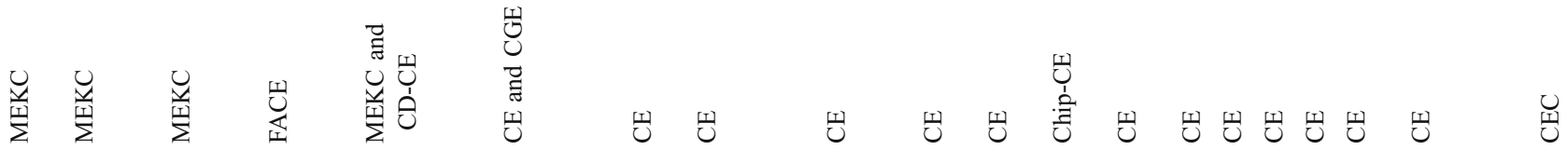
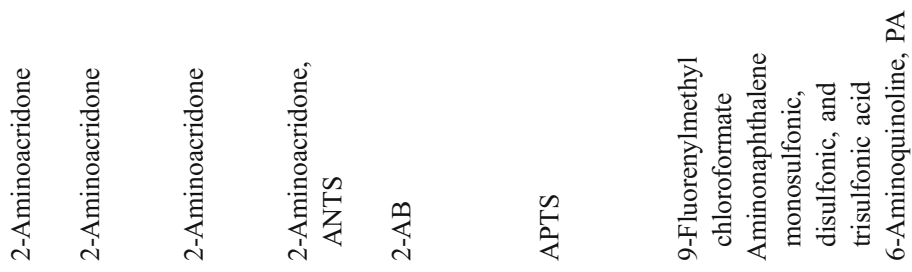

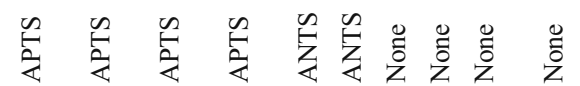
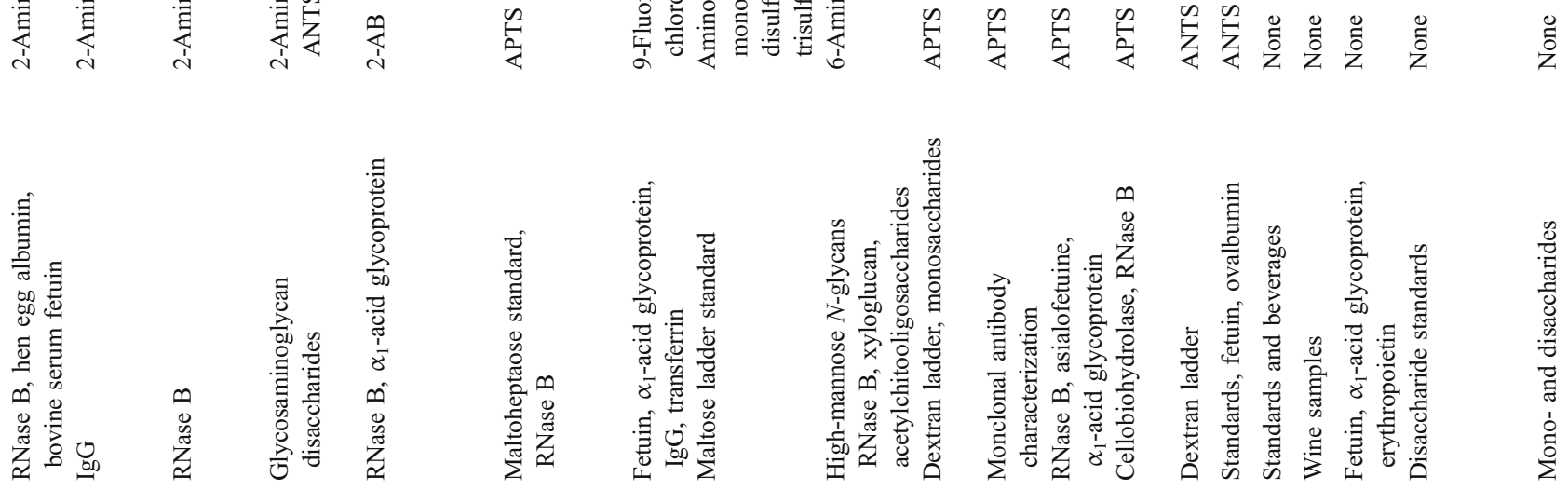


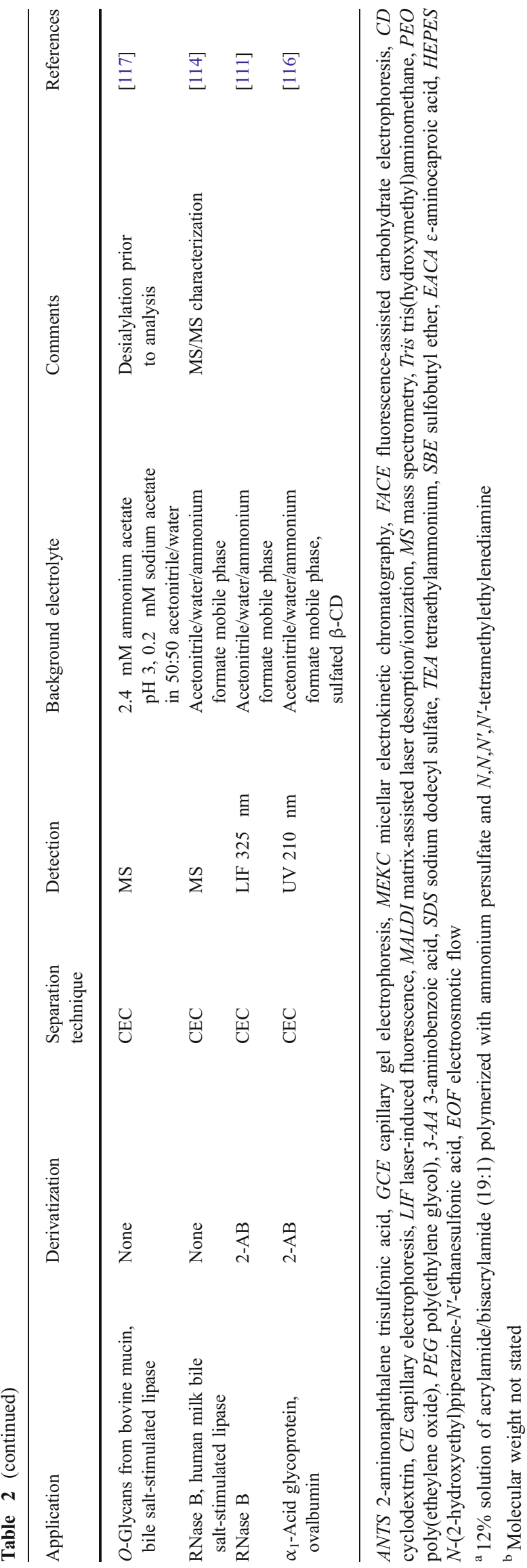

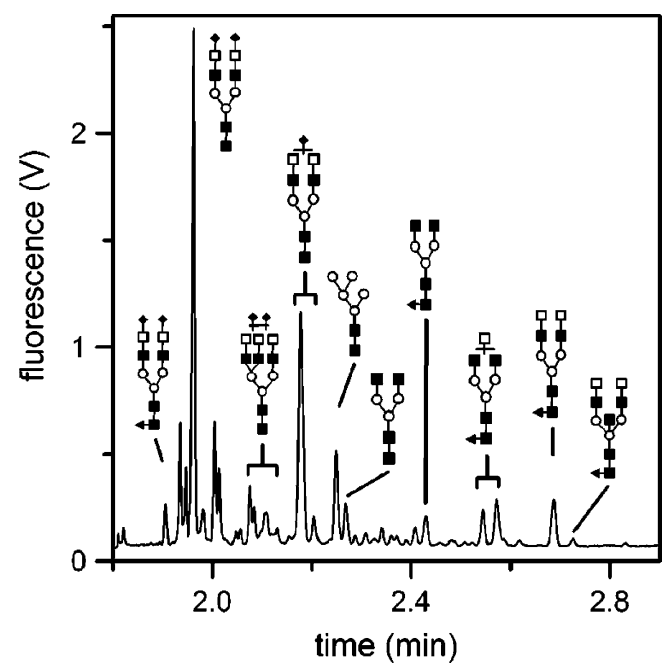

Fig. 3 Separation of 1-aminopyrene-3,6,8-trisulfonic acid labeled glycans on a microfluidic device in $1 \mathrm{mM}$ phosphate and $20 \mathrm{mM} \mathrm{N}$ (2-hydroxyethyl)piperazine- $N$ '-ethanesulfonic acid $\mathrm{pH}$ 6.8. Glycans were released from a blood sample of a stage IV breast cancer patient. (Taken from [103] with permission)

size-dependent separation can be introduced using MEKC or CGE, enabling the separation of structural isomers. Sometimes borate is used to further enhance the separation selectivity $[106,107]$. A number of methods for 2-AA- and APTS-labeled glycans have been published, mainly including polyethylene glycol (molecular weight 20,000$300,000)$ as the sieving matrix [36, 108-110]. Multiplexing using a DNA sequencer has been developed for highthroughput glycoprofiling of APTS-labeled glycans [37, 38, 77]. The major disadvantage of CGE-based methods is their incompatibility with MS, so the identification of signals is complicated and can only be achieved by standards or additional experiments such as the reanalysis of the sample after exoglycosidase treatment $[36,37,110]$. In recent years there has thus been an increase in the use of capillary electrochromatography for the analysis of glycans [111117]. This technique allows charge-based separation driven by the external electric field, but also provides orthogonal chromatographic interaction for enhanced selectivity. Further growth of this approach can be anticipated, especially when it is used in combination with MS.

Most work using electromigrative separation techniques has focused on the identification of glycans. However, CE has also been used to semiquantitatively compare glycan peak area ratios in CE-MS [104].

Several strategies for glycan and oligosaccharide analysis using electromigrative separation techniques have been presented in the literature, differing in their way to achieve separation:

1. Direct analysis: High-pH BGEs are applied to achieve the dissociation of the oligosaccharide hydroxyl groups 
to obtain electrophoretic mobility for the glycans. Alternatively, a focus on sialylated and phosphorylated glycans is possible; the neutral glycans are then only transported by electroosmotic flow and are not further separated. The analysis of nonlabeled glycans is possible using direct UV detection at a very low wavelength [118] or indirect detection with appropriate probes added to the BGE [118-121]. Also MS [104, 122] and electrochemical detection [123] can be applied.

2. Introduction of charged carriers: Several metal acids have been shown to complex with vicinal diol groups mainly via cis-diols, but also via trans-diols [106, 107], and thus they introduce a charge on the glycan. Borate or boronic acids are mostly used [124, 125]. These complexing agents can also be added to the BGE at lower concentration to enhance resolution by changing the separation selectivity, when labels are applied [36, $109,110,126]$. MEKC can in principle be used for the analysis of unlabeled glycans; however, owing to detection restrictions, it has mainly been used for the separation of labeled glycans (neutral labels were applied such as 2-aminoacridone [98, 127-129] and 2-AB) by charged cyclodextrins as separation carriers [98].

3. Introduction of labels: Glycan labeling mainly has two functions in electrophoretic separation techniques: On the one hand, labels enable or facilitate fluorescence or MS detection; on the other hand, they enhance or in the case of neutral glycans allow the separation by introducing a charge on the glycans, thus allowing electrophoretic mobility. We can distinguish between neutral tags (only applied for detection purposes), cationic tags, and anionic tags.

Neutral tags are only rarely applied for electromigrative separation techniques as the electrophoretic mobility has then to be achieved by other means; only sialylated glycans may be considered, or alternatively MEKC using charged micellar carriers may be applied. Examples are the use of 2$\mathrm{AB}$ [98] or 9-fluorenylmethylchloroformate on the amine function after release [130]. Several cationic labels have been applied for the analysis of monosaccharides, such as 6-aminoquinoline [131, 132], dansylhydrazine [133], benzoylhydrazine [134], aminopyridine [131], and aminoacridone [127-129]. Their use for complex glycans containing sialic acids is not recommended, as it would be difficult to have all glycans with an observed electrophoretic mobility towards the detector: neutral glycans (regarding only the glycan core) will be positively charged, whereas for sialylated glycans an overall cationic charge cannot always be achieved, leading to a mixture of cations and anions to be separated and transported towards the detector. Most work regarding the analysis of glycans with electromigrative separation techniques has thus been done using anionic labels, with APTS, ANTS, 3-aminobenzoic acid, and 2-AA most frequently applied (see Table 2). APTS, with three charged sulfonic acid groups, can be used over a large $\mathrm{pH}$ range, whereas for the analysis of aminobenzoic acid labeled glycans containing sialic acids a more basic $\mathrm{pH}$ is recommended to achieve an overall negative charge for all glycans.

\section{Chromatographic separation}

Chromatographic separation of glycans may be performed by adsorption chromatography, which is mostly done in the HPLC mode, by gel permeation chromatography (sizeexclusion chromatography [148]), or by (capillary) gas chromatography $[85,149]$. The latter technique is used for the analysis of monosaccharides in glycoconjugate composition analysis [149] or linkage analysis [85]. This section is restricted to adsorption chromatography for glycan analysis, as most of the recent chromatographic developments in glycan analysis have occurred in this field. Moreover, the focus will be on HPLC separations, and other, mostly older adsorption chromatographic techniques will be omitted, such as paper chromatography and thin layer chromatography of monosaccharides combined with radioactive detection using reductive labeling of the reducing end with tritium $[150,151]$.

\section{Hydrophilic interaction liquid chromatography}

HPLC-mode HILIC is a widely applied technique for oligosaccharide separation [152-154]. The most commonly used stationary phases comprise amine-bonded silica, amide-bonded silica, and ZIC HILIC phases [31, 152154]. Also, diol phases are widely used [155]. Hydrogen bonding is often the major retention mechanism.

To be used in a pure HILIC mode (without anion exchange present), amine-bonded phases require rather high ionic strengths, which lead to the suppression of ionic interactions of acidic groups on the glycan such as sulfate and carboxyl groups of sialic acids with the ammonium groups of the stationary phase. Typically, volatile buffers such as acetic acid/triethylamine are applied at concentrations of up to $200 \mathrm{mM}$ [156]. The use of amine-bonded phases at lower ionic strength results in a mixed-mode HILIC/anion-exchange separation, which is discussed later.

With ZIC-HILIC, where silica beads or polymer beads are functionalized with zwitterionic sulfobetaine groups, the retention properties of sialylated PA-labeled glycans change when $20 \mathrm{mM}$ ammonium acetate is used instead of $5 \mathrm{mM}$ ammonium acetate in the solvent, whereas the retention properties of neutral glycans are not influenced, pointing to a combination of ionic and nonionic interactions on these (mixed-mode) phases [31]. 
With amide and diol phases, ionic interactions play only a minor role and are mainly caused by the remaining bare silica groups of the carrier material. Therefore, these phases may be used in pure HILIC mode also at low salt concentrations such as $50 \mathrm{mM}$ ammonium formate, $\mathrm{pH}$ 4.4 [29]. Typical equilibration conditions in HILIC HPLC of monosaccharides and oligosaccharides are 10-25\% water in acetonitrile with a low concentration of acid or salt (mostly below $100 \mathrm{mM}$ ). Elution is accomplished by a gradient which increases the aqueous fraction of the mobile phase to typically $50 \%$.

To allow for sensitive detection in HILIC, glycans are almost always labeled with a chromophore or a fluorophore. The most commonly used labels are PA [93], 2-AB [29], and 2-AA [34], but other tags such as 3-(acetylamino)-6aminoacridine [157] have also been used. As most of these labels have hydrophobic characteristics, the derivatized glycans show slightly less retention than native, unlabeled glycans. Fluorescence detection is mostly performed using detectors equipped with a xenon lamp and both excitation and emission monochromators can be set to the optimal wavelengths of the chosen label to achieve high sensitivity.

HILIC is sometimes referred to as "size separation", owing to the correlation between glycan size and its retention time. However, the contribution of added monosaccharides to oligosaccharide retention may vary considerably, depending on the composition of the sugars of the glycan. Generally speaking, hexoses tend to give a larger (increase of) retention than $\mathrm{N}$-acetylhexosamines of deoxyhexoses (fucoses) [23, 29]. HILIC also has a considerable potential to separate structural isomers [158-162]. For example, core-fucosylated biantennary monogalactosylated $\mathrm{N}$-glycans which carry the galactose on the 6-antenna (isomer 1) or 3-antenna (isomer 2) are partially separated by HILIC after labeling with 3(acetylamino)-6-aminoacridine [157].

HILIC separations with fluorescence detection can be performed in a very robust manner. Fluctuations in retention times can be compensated by performing a standardization of elution properties using a glucose ladder (partial dextran hydrolysate). The time axis may then be normalized to an axis of glucose units (GUs), relating the oligosaccharide migration properties to the elution positions of these glucose oligomers [29]. Rudd and coworkers have established a database (GlycoBase and autoGU) which allows the structural assignment of 2-AB-labeled oligosaccharides on the basis of migration positions on a TSK-amide- 80 column. In this database, GUs are listed for 2-AB-labeled glycans before and after cleavage by exoglycosidases [29, 163]. Recently, the use of smaller ( $3 \mu \mathrm{m}$ instead of $5 \mu \mathrm{m})$ amide-coated HILIC particles has led to a marked reduction of analysis times [29, 157], which makes HILIC in combination with fluorescence detection a suitable method for intermediate- to highthroughput glycosylation analysis [29, 164].
A detailed overview of glycosylation analysis by HILIC with mass-spectrometric detection has recently been provided [152]. Mass-spectrometric detection of both labeled and unlabeled glycans is compatible with HILIC separation, particularly when amide or diol phases are used, owing to the low concentrations of acid or volatile salt combined with the relatively high percentages of acetonitrile, which is beneficial for ESI [152, 155]. To allow high-sensitivity detection, HILIC separation in combination with ESI-MS is often performed in miniaturized form down to the nanoscale $[152,159,160,165]$, allowing the detection of low femtomole amounts of glycan (absolute amount injected) in both native [160] and 2-AB-labeled form (Fig. 4) [159]. Similar to HILIC with fluorescence detection, HILIC with nano-ESI-ion trap-MS can make use of GUs when a 2-ABlabeled dextran ladder is applied as an internal standard. In this case, however, the primary information for glycan identification and structural elucidation is glycan mass and tandem MS data, and the GUs have a supporting role [159]. Alternatively, HILIC fractions may be analyzed by with MALDI-TOF(/TOF)-MS(/MS) detection, which may be combined with high-energy fragmentation of sodium adducts [161, 162]. HILIC-MS is particularly useful for the in-depth analysis of complex oligosaccharide mixtures owing to its potential to separate glycans of different structures and identify isomers [158-162]. The proven usefulness of HILIC-MS for the analysis of complex oligosaccharide mixtures [156-160] will surely lead to its widespread application in the future.

\section{Mixed-mode HILIC/anion exchange separation}

Some authors have chosen to combine ionic interaction with hydrophilic interaction in mixed-mode HILIC/anion exchange separations of 2-AA-labeled glycans [74, 166]. These separations are performed on amine-bonded columns, which owing to (partial) protonation exhibit anionexchange properties [74], or on a strong anion exchange HPLC column functionalized with quaternary ammonium groups [166]. The contribution of ionic interactions of both the tag and the glycan can be modulated by changing the ionic strength of the eluents (see "Hydrophilic interaction liquid chromatography"), whereas hydrophilic interactions (hydrogen bonding) with the stationary phase are influenced by the water content of the eluents. By carefully tuning the two interaction modes, optimized gradients result in the separation of glycan groups that differ in charge (Fig. 5). Within each charge group, separation is accomplished on the basis of HILIC. The separations obtained for glycans with different degrees of sialylation resemble somewhat those obtained by high-pH anion-exchange chromatography (HPAEC) of unlabeled glycans [74]. 
Fig. 4 Subfemtomole sensitivity of nanoscale liquid chromatography (LC)-electrospray ionization (ESI)-mass spectrometry (MS) in the analysis of a 2-

aminobenzamide (2-AB)-labeled hexamannosidic $N$-glycan $\left(\mathrm{Man}_{6-}\right.$ $\mathrm{GlcNAc}_{2}$ ). A 2-AB-labeled hexamannosidic $N$-glycan was analyzed using nanoscale hydrophilic interaction LC (HILIC)-

ESI-ion trap-MS. Base-peak chromatograms of a dilution series show that the detection of as little as 2 fmol of 2-AB-tagged $\mathrm{Man}_{6-}$ GlcNAc$_{2}$ injected is possible $(A)$. Sum mass spectra of the elution range of $\mathrm{Man}_{6} \mathrm{GlcNAc}_{2}$ (25.2$26 \mathrm{~min} ; B-E$ ) revealed the detection of proton adducts $(\mathrm{m} / \mathrm{z} 1,517)$ and sodium adducts $(\mathrm{m} / \mathrm{z} 1,539)$ down to 0.5 fmol of injected standard $(E)$. Combined selected ion chromatograms for $\mathrm{m} / \mathrm{z} 1,517$ and $m / z 1,539$ allowed the detection of the standard after injection of a 2 -fmol as well as a 0.5 -fmol aliquot (inset in $A$ ). (Reproduced from [159] with permission)
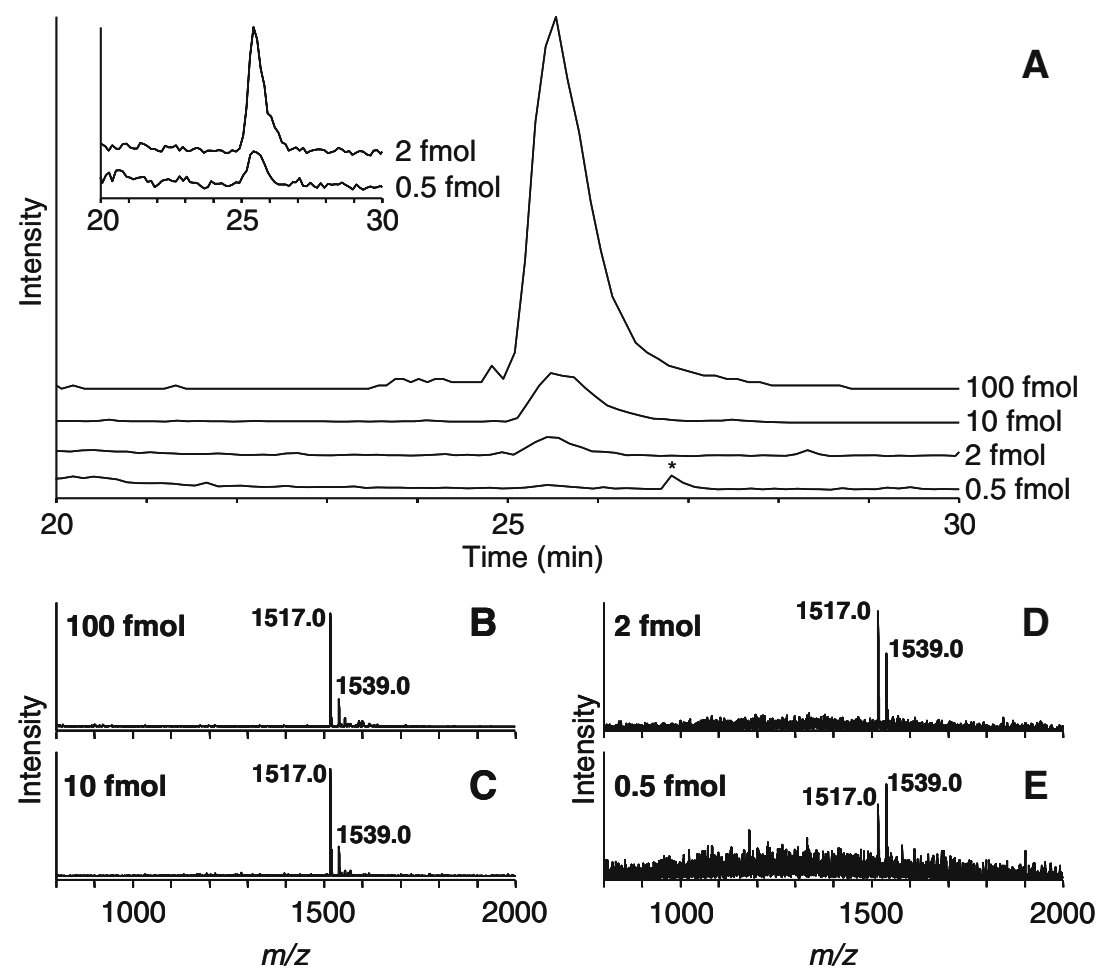

\section{Anion-exchange chromatography}

Many glycan fractionation schemes include preparative anion-exchange chromatography with fluorescence detection of glycans labeled with PA or 2-AB [92, 93]. Anion-

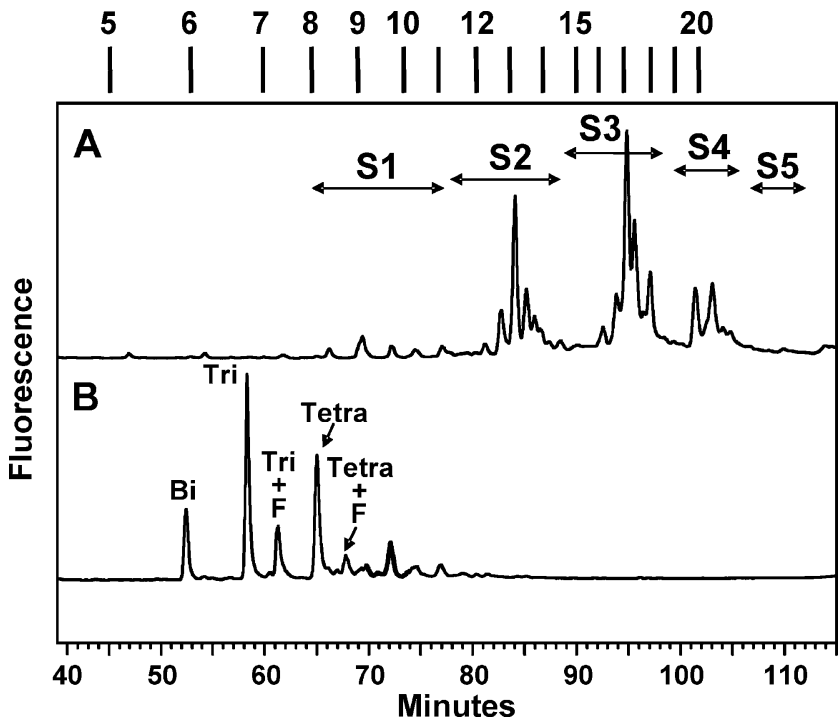

Fig. 5 Mixed-mode HILIC/anion exchange separation of $\alpha_{1}$-acid glycoprotein oligosaccharides before (a) and after (b) desialylation. $S 1-S 5$ refer to the number of sialic acid residues present in the oligosaccharides. Bi, Tri, Tri $+F$, Tetra, and Tetra $+F$ refer to biantennary, triantennary, fucosylated triantennary, tetraantennary, and fucosylated tetraantennary $\mathrm{N}$-linked oligosaccharides, respectively. (Reproduced from [166] from with permission) exchange chromatography of glycans is typically performed at neutral to slightly alkaline $\mathrm{pH}$. Under these conditions, the charge of most glycans is determined by the presence of carboxylic acids, sialic acids, glucoronic acids, sulfates, and phosphates. The separation is based on the (negative) charge of the glycans determined by these substituents. Elution is often accomplished by a salt gradient, which hinders the combination with mass-spectrometric detection. Anion-exchange chromatography may be followed by HILIC separation of the charged groups obtained after desialylation to the simplify elution patterns [167].

\section{High-pH anion-exchange chromatography}

In contrast to classic anion-exchange chromatography, HPAEC is performed at a $\mathrm{pH}$ of approximately 13. Under these conditions, hydroxyl groups on glycans are partially deprotonated, resulting in a partial negative charge, which is then used for the separation of the glycans. Glycans with a reduced end exhibit less retention than reducing-end glycans, as they lack the anomeric hydroxyl group which is a major contributor to the partial negative charge. Usually electrochemical detection (pulsed amperometric detection, PAD) is applied for the analysis after HPAEC separation. HPAEC is suitable for the separation of nonderivatized glycans as well as glycans with various types of labels and modifications.

Kotani and Takaski [168] reported the analysis of Nlinked oligosaccharides released from various glycoproteins labeled with 2-AB using HPAEC with PAD followed by in- 
line neutralization of the eluent with an anion micromembrane suppressor to allow for fluorescence detection. In their hands, high $\mathrm{pH}$ led to quenching of the fluorescence intensity, which made postcolumn neutralization necessary. Moreover, they observed a better chromatographic resolution for 2-ABlabeled asialooligosaccharides released from human $\alpha_{1}$-acid glycoprotein by HPAEC than by HILIC (Fig. 6).

Ridley et al. [169] reported a method for biotin labeling of biologically active oligogalacturonides using a stable hydrazide linkage after first creating the water-instable hydrazone derivative. With use of HPAEC-PAD, optimization of the reaction conditions was monitored, product yields were determined, and a subsequent stability test was performed. It could be concluded that the yield of the oligogalacturonide-biotin hydrazide derivatives is dependent on the size of the oligogalacturonide.

Stubbs et al. [170] described a semipreparative purification of tetraantennary oligosaccharides from human $\alpha_{1}$-acid glycoprotein. Six tert-butoxycarbonyl-L-tyrosine oligosaccharide derivatives were purified and the subsequent labeling process was monitored by HPAEC-PAD. The chromatographic resolution of tert-butoxycarbonyl-L-tyrosine derivatives of the oligosaccharides with HPAEC-PAD was

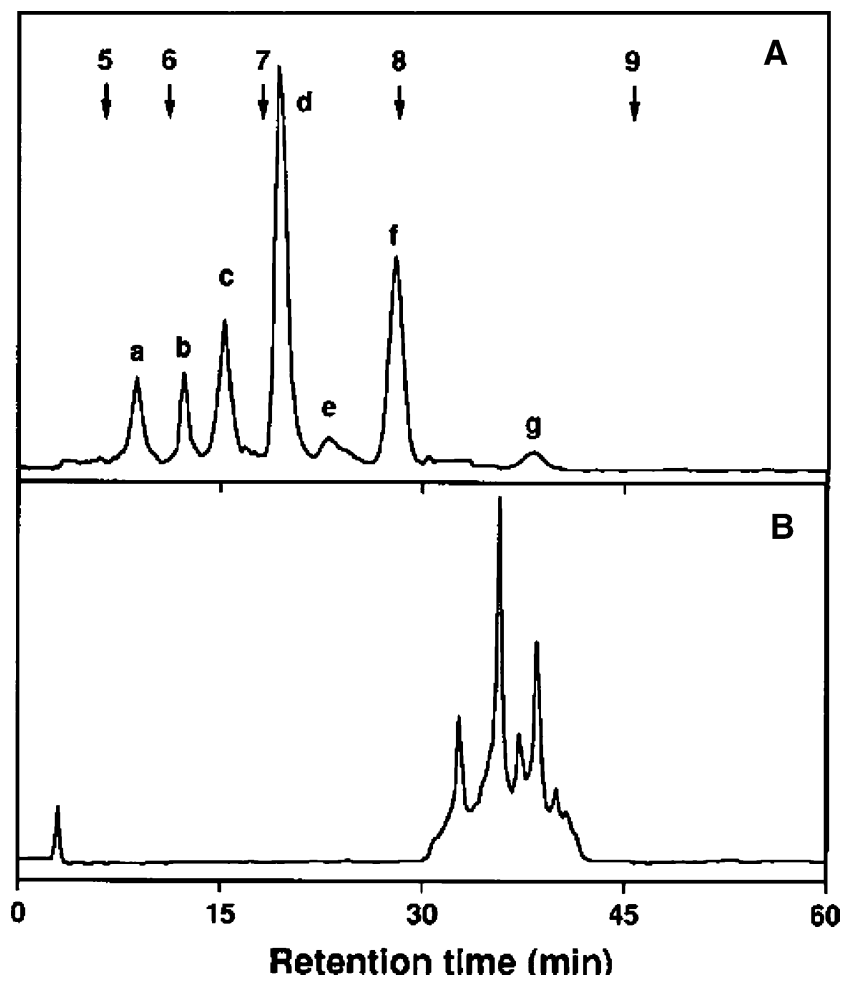

Fig. 6 Analysis of N-linked oligosaccharides from human $\alpha_{1}$-acid glycoprotein. 2-AB-labeled oligosaccharides obtained were analyzed by high-pH anion-exchange chromatography with fluorescence detection (a) or high-performance LC (HPLC) with an amide-80 column and fluorescence detection (b). (Reproduced from [168] with permission) comparable to that of the free oligosaccharides. Closely related to this publication [170] is the work by Collard et al. [171], in which HPAEC-PAD was applied to monitor a time course of the elimination of the tert-butoxycarbonyl (BOC) group from a BOC-tyrosinamide-labeled triantennary $\mathrm{N}$ glycan, followed by reductive alkylation/formylation resulting in dimethylation of the tyrosinamide moiety.

\section{PGC chromatography}

PGC stationary phases are often used for the separation of oligosaccharide alditols, fluorescently labeled glycans, and even permethylated glycans [66], as reviewed recently [84]. Retention is mediated by a combination of predominantly ionic and hydrophobic interactions [84], and elution is often achieved by a gradient of organic solvents with addition of small amounts of volatile salts, acids, or bases, making PGC of oligosaccharides compatible with mass-spectrometric detection [84].

Both small and large oligosaccharides show retention on PGC. Moreover, glycans with a reducing-end tag as well as native glycans may be applied. PGC is the separation method of choice for direct liquid chromatography (LC)MS analysis of $O$-glycans which have been released by reductive $\beta$-elimination, as these glycans are often rather small and do not contain a reducing end for labeling [172, 173]. Next to native or reduced glycans, fluorescently labeled glycans have often been analyzed using PGC [84]. The fluorescent labels contribute to the retention of glycans on PGC: PA, which is a label with only modest retention in PGC, results in superb PGC separations of labeled glycans, whereas derivatization with a label such as $2-\mathrm{AB}$, which has pronounced influence on glycan retention on PGC, results in inferior resolution [174]. Notably, PGC is very efficient in separating structural isomers. Retention times in combination with glycan mass analysis are often sufficient for structural assignment $[175,176]$.

\section{$R P$ chromatography}

The aspect of hydrophobic interactions between (labeled) oligosaccharides and the stationary phase is common for both PGC and RP separations on $\mathrm{C}_{18}$ phases. In contrast to PGC separation, however, RP-HPLC of oligosaccharides requires derivatization, because the retention of underivatized glycans is often insufficient [177]. For labeled glycans, the retention properties are determined by a combination of the hydrophobic properties of the tag and the contribution of monosaccharide residues [75]. The effect of the addition of monosaccharides on the retention of a labeled glycan may differ depending on the tag: $\mathrm{N}$ glycans labeled with PA, which is a low-retention tag, showed increasing retention with a higher degree of 
antenna galactosylation, whereas the same set of $\mathrm{N}$-glycans labeled with 2-aminobenzoic acid ethyl ester showed decreasing retention with a higher degree of antenna galactosylation [75].

For fluorescence detection in RP-HPLC, the most commonly applied tags are PA [93, 178] and 2-AB [179, 180]. Together with HILIC and anion-exchange chromatography, RP-HPLC with fluorescence detection is used in multidimensional mapping strategies for structural assignment of PA-labeled $N$-glycans [93].

Next to fluorescence detection, RP-HPLC is often combined with online ESI-MS analysis, which has been shown for glycans labeled with various tags such as PMP, phenylhydrazine, and the biotin label BACH [55, 78, 181, 182]. Moreover, both 2-AB-labeled and 2-AA-labeled $\mathrm{N}$-glycans can be analyzed by RP-nanoLC-MS/MS, and separations of structural isomers have been demonstrated [83, 179, 180, 183]. Chen and Flynn [180] have impressively demonstrated the separation power of RP-HPLC of 2-AB-labeled glycans, and have combined this with both positive-mode and
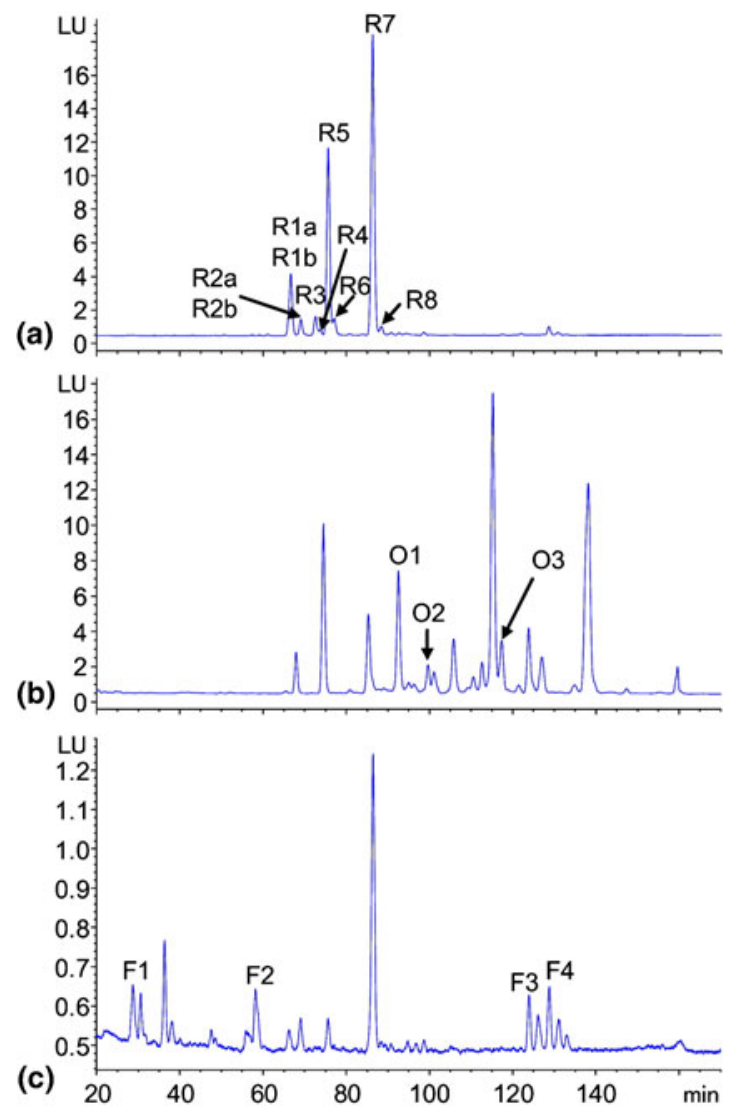

Fig. 7 Reverse-phase HPLC with fluorescence detection of 2-ABlabeled glycans released from a $10 \mu \mathrm{g}$ RNase B, b $30 \mu \mathrm{g}$ ovalbumin, and c $30 \mu \mathrm{g}$ fetuin. The structures of the labeled oligosaccharide peaks are shown in d. Species that were coeluted in the same fluorescence peak are indicated by letters $a$ and $b$. The peaks corresponding to the species that were eluted early (less than $20 \mathrm{~min}$ ) containing two or negative-mode multistage tandem MS on an ion trap mass spectrometer for structural assignment (Fig. 7).

Alternatively, nanoscale RP-HPLC-MS/MS of labeled glycans may be performed without fluorescence detection. A major advantage of this approach is that the necessary analytical equipment is available in many proteomics and metabolomics laboratories: columns (nano-RP $\mathrm{C}_{18}$ ) as well as solvents (water/acetonitrile mixtures containing typically $0.1 \%$ of formic acid) which are used for the LC-MS analysis of complex peptide mixtures can be directly used for the analysis of 2-ABlabeled [83, 183] and 2-AA-labeled glycans (unpublished results) without any adjustment.

Permethylated glycans may likewise be analyzed by RPHPLC-MS. Structural isomers of permethylated glycans are separated using this approach [184]. This method in particular has potential for in-depth structural characterization of glycans by tandem MS of sodium adducts, which has hitherto predominantly been applied without a preceding separation [63].
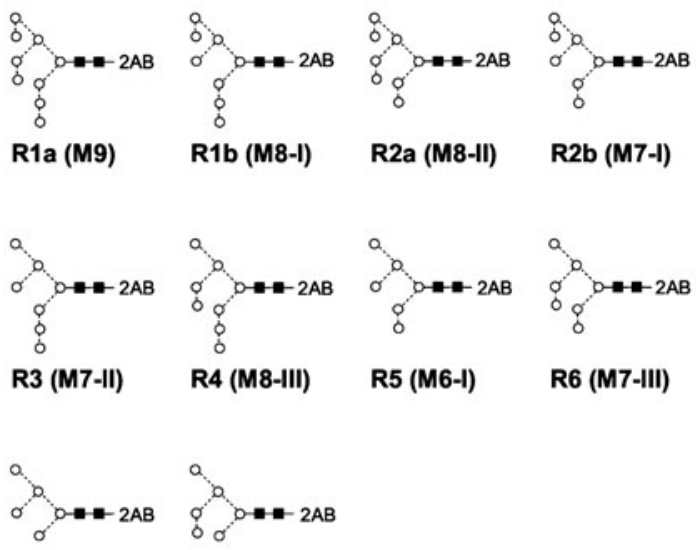

R7 (M5) R8 (M6-II)
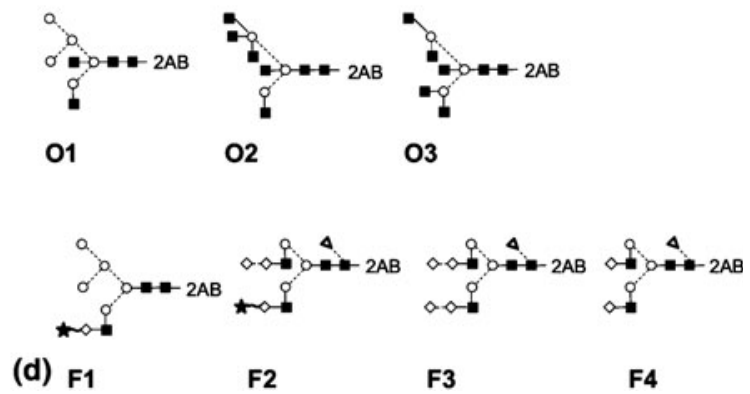

more sialic acids are not shown. Circles mannose, squares GlcNAc, diamonds galactose, triangles fucose, stars sialic acid, dashed lines $\alpha$ linkage, solid lines $\beta$ linkage, vertical lines 1-2 linkage, horizontal lines 1-4 linkage, forward slashes 1-3 linkage, backslashes 1-6 linkage; wavy lines unknown linkage. (Reproduced from [180] with permission) 
A comparative study analyzing PMP- and ANTS-labeled glycans was performed by Saba et al. [78], where the ANTS labeling was accomplished by reductive amination. Overall, PMP-modified oligosaccharides yielded better normal and RP separation and improved sensitivity than the ANTS-labeled sugars for LC-ESI-MS analysis [78]. This approach could facilitate the structural investigation of various oligosaccharides in the future.

\section{Mass spectrometry}

\section{Glycan ionization and detection}

Both ESI-MS and MALDI-MS are often used for massspectrometric analysis of glycans. ESI of glycans is most often used in-line with HPLC or CE (see "Separation and detection"), which may be used for quantification in combination with (isotope) labeling (see "Comparative glycomics by MS"). Here, off-line ESI-MS and MALDI-MS of glycans are discussed with a focus on derivatization techniques.

The ionization efficacies of oligosaccharides are markedly influenced by charged substituents of the glycan such as carboxyl groups of sialic acid or glucoronic acid and sulfate groups, which promote negative-mode ionization. Moreover, derivatization influences the ionization efficacies by introducing additional charges. Glycans with negatively charged substituents are more efficiently ionized in negative-ion mode than their neutral counterparts, whereas native as well as labeled glycans lacking acidic substituents are predominantly analyzed using positive-mode ionization [185]. Notably, the influence of charged substituents on ionization efficacies is much more pronounced in MALDI than in ESI. In addition, derivatization often gives the oligosaccharide a more hydrophobic character, which usually increases ESI efficacies. Next to their pronounced effect on ionization, labels influence the fragmentation behavior of glycans and may help with the assignment of fragmentation spectra by tagging the reducing end.

\section{Off-line ESI-MS}

Off-line ESI-MS of glycans is performed on both native and permethylated glycans. Off-line ESI-MS of native glycans is mostly applied for structural analysis by tandem MS and is possible in both negative-ion and positive-ion mode.

In positive-ion mode, some sodium salt is usually added to the spray solvent consisting typically of a water/ methanol mixture containing a volatile acid (formic acid or acetic acid) [186]. The sodium ions suppress the formation of proton adducts. The resulting sodium adducts are more stable than proton adducts and less prone to insource decay during ion transfer from atmospheric pressure to a vacuum. Thus, a better sensitivity and less complex structures are obtained. Moreover, whereas tandem MS of proton adducts by CID usually exclusively results in the fragmentation of glycosidic bonds, CID of sodium adducts additionally results in cross-ring cleavages providing linkage information [186]. Negative-mode ionization and fragmentation has been applied by Pfenninger et al. [187, 188] and more recently by Harvey [189-191], who optimized the offline ESI conditions, resulting in the registration of (multiple) deprotonated species and/or anion adducts (phosphate, nitrate, or chloride). Tandem MS of negatively charged oligosaccharide ion species usually provides specific crossring cleavages allowing structural elucidation.

Notably, fragmentation of sodium adducts and deprotonated species of specific glycans result in very different patterns of cross-ring cleavages [192]. Negative-mode tandem MS of oligosaccharides is characterized by a considerable stability of fucose glycosidic linkages, in contrast to positivemode tandem MS, where fucose bonds are labile [192].

The most commonly applied labeling technique for offline positive-mode ESI is permethylation. Compared with native glycans, permethylated glycans generally give higher MS signals. Moreover, permethylation allows purification/ desalting of the glycans by liquid-liquid extraction or RPSPE (Table 1). Tandem mass spectra of sodium as well as other alkali ion adducts of permethylated glycans provide very informative tandem MS spectra: the methyl substitution pattern allows the discrimination between terminal, internal, and branching monosaccharide residues. Cross-ring cleavages are extensive, providing linkage information. The mass spectrometer of choice is the ion trap, which allows multiple ion isolation/fragmentation cycles for in-depth structural characterization. The power of this approach was demonstrated by Prien et al. [63] by characterizing isomers of RNase B $\mathrm{N}$-glycans, some of which were described for the first time.

\section{Matrix-assisted laser desorption/ionization MS}

In contrast to ESI-MS, which is often used online with separation techniques, MALDI-MS of glycans is predominantly used as a stand-alone technique. MALDI-MS of native glycans is mostly performed in positive-ion mode using 2,5-dihydroxybenzoic acid (DHB) as the matrix substance, resulting in the registration of sodium adducts. Negative-mode detection of neutral native glycans, in contrast, is difficult to achieve and may require specific matrices and additives [192].

Permethylation is often used in combination with MALDI-TOF-MS detection, resulting in the very sensitive detection of glycans, mostly as sodium adducts $[22,72,85$, 193]. Permethylation transforms the carboxyl groups of sialic acid residues into methyl esters, which are far less labile than the underivatized sialic acid groups, thereby 
allowing the MALDI-TOF-MS analysis of glycans without loss of sialic acids by in-source and metastable decay [22].

Another labeling method which is used in combination with MALDI-TOF-MS analysis of glycans is the derivatization with carboxymethyl trimethylammonium hydrazide (Girard's reagent T) [60]. This label induces a permanent positive charge at the reducing end and thereby allows very efficient generation of glycan ions. Labeling of glycans by reductive amination has several consequences for MALDI: the (secondary) aromatic amine group introduced in this reaction (see Fig. 2a) makes glycans labeled with PA, 2-AB, and 2-AA readily protonable. Thus, MALDI-MS of these glycans often results in the detection of proton adducts next to sodium adducts. With regard to negative-mode MALDI, the 2-AA tag - owing to its carboxyl group - makes neutral glycan structures readily ionizable, thereby allowing the joint registration of sialylated and nonsialylated glycans in one MALDI spectrum [34]. When sialylated glycans are analyzed, reflectron-mode MALDI-TOF-MS often shows partial or complete loss of sialic acids, which is due to insource decay and metastable decay. Loss of sialic acids is somewhat less pronounced in negative-ion mode. Moreover, a reduction of decay problems may be achieved by applying alternative matrices such as 2,4,6-trihydroxyacetophenone, which is colder than DHB [194]. In contrast, a hot matrix such as $\alpha$-cyano-4-hydroxycinnamic acid leads to a more pronounced desialylation. Notably, loss of sialic acid is hardly seen when MALDI-TOF-MS is performed in linear mode [34]: metastable decay still occurs under these conditions, but the resulting fragments are not visible. Acceleration starts immediately after ionization/desorption, and fragment ions arising thereafter in the field-free region will not be resolved.

Although MALDI-TOF-MS instruments generally require a source pressure in the range of $10^{-6} \mathrm{mbar}$, MALDI with other MS detectors may alternatively be performed at intermediate pressures (typically submillibar range). Under such conditions, the loss of sialic acids is suppressed: using DHB as a matrix, intermediate-pressure MALDI-Fourier transform ion cyclotron resonance (FTICR)-MS allows the high-resolution analysis of both sialylated and nonsialylated, 2-AA-labeled $\mathrm{N}$-glycans from human plasma with virtually no in-source decay (Fig. 8). Our results show that loss of sialic acids is avoided by collisional cooling of ions in the ion source at intermediate-pressure conditions. Moreover, compared with MALDI-TOF-MS, relatively low extraction voltages are applied in the ion source.

\section{Comparative glycomics by MS}

Most often, relative quantification of glycoforms within one sample is achieved using MS (with or without preceding separation) or by LC or CE with fluorescence detection (see
"Separation and detection"). Comparison of a large number of glycan samples by mass-spectrometric analysis may be compromised by changes in the performance of the mass spectrometer over time, and also because of the large number of sample preparation steps necessary, possibly introducing unwanted bias, e.g., loss of sialic acids. Especially the labeling step itself can be problematic with respect to labeling efficiency, interference by matrix components, or the subsequent purification step. We have recently established a high-throughput method for glycosylation profiling of the total plasma $N$-glycome by negative linear-mode MALDI-TOF-MS after glycan release and 2-AA labeling. Similarly, N-glycosylation profiling can be performed with permethylated glycans, which has the advantage that sialic acid groups are stabilized by methyl ester formation [22, 69-71].

In proteomics approaches, labeling with isotopic or isobaric tags is often employed to obtain good quantification results [195]. Some research groups have now started to incorporate the idea of isotopic [40-44, 196-198] as well as isobaric $[61,91]$ labeling also for glycomics analysis (see also "Reductive amination").

Isotopic derivatives share the same atomic composition, but have different masses owing to the introduction of heavy isotopes, most often D and ${ }^{13} \mathrm{C}$. Several reports of use of this approach for comparative glycomics have been published: Many of the isotopic derivatives, such as $\left[\mathrm{H}_{4}\right] \mathrm{PA}$ versus $\left[\mathrm{D}_{4}\right] \mathrm{PA}[40],\left[\mathrm{H}_{4}\right] 2-\mathrm{AA}$ versus $\left[\mathrm{D}_{4}\right] 2-\mathrm{AA}[41]$, and $\left[{ }^{12} \mathrm{C}_{6}\right]$ alanine versus $\left[{ }^{13} \mathrm{C}_{6}\right]$ alanine $[43,44]$, are introduced by reductive amination (see "Reductive amination"). The PA-labeled monosaccharides were analyzed by PGC-LCMS, and the observed relative standard deviations (RSDs) were less than $7.2 \%$ [40]. Derivatization of a dextran ladder with aniline and subsequent analysis using HILIC-LC-MS resulted in RSDs below $10 \%$ for $\mathrm{Hex}_{3}-\mathrm{Hex}_{5}$. Larger oligosaccharides had larger RSDs [44]. In a second study, an RSD of $4.85 \%$ was observed for lacto- $N$-neotetraose derivatized with aniline followed by HILIC-LC-MS analysis with a large dynamic range [43].

The incorporation of an isotopic tag by permethylation has been described by Alvarez-Manilla et al. [196]. Oligosaccharides are permethylated using either ${ }^{12}[\mathrm{C}] \mathrm{H}_{3} \mathrm{I}$ or ${ }^{13}[\mathrm{C}] \mathrm{H}_{3} \mathrm{I}$, resulting in a $1 \mathrm{Da}$ mass difference per permethylation site. Derivatization of $\mathrm{Hex}_{3}-\mathrm{Hex}_{5}$, followed by MALDI-TOF-MS analysis revealed an average RSD of $12.7 \%$ over a linear dynamic range of 2 orders of magnitude. Differentially labeled glycans from $\alpha_{1}$-acid glycoprotein were mixed 1:1, resulting in an average RSD for seven glycoforms of $6 \%$.

However, these approaches only allow for the comparison of one sample pair at a time, in contrast to proteomics labeling techniques such as iTRAQ enabling the comparison of up to eight samples [199]. Recently, Bowman and Zaia [197] synthesized different tags on the basis of 2- 

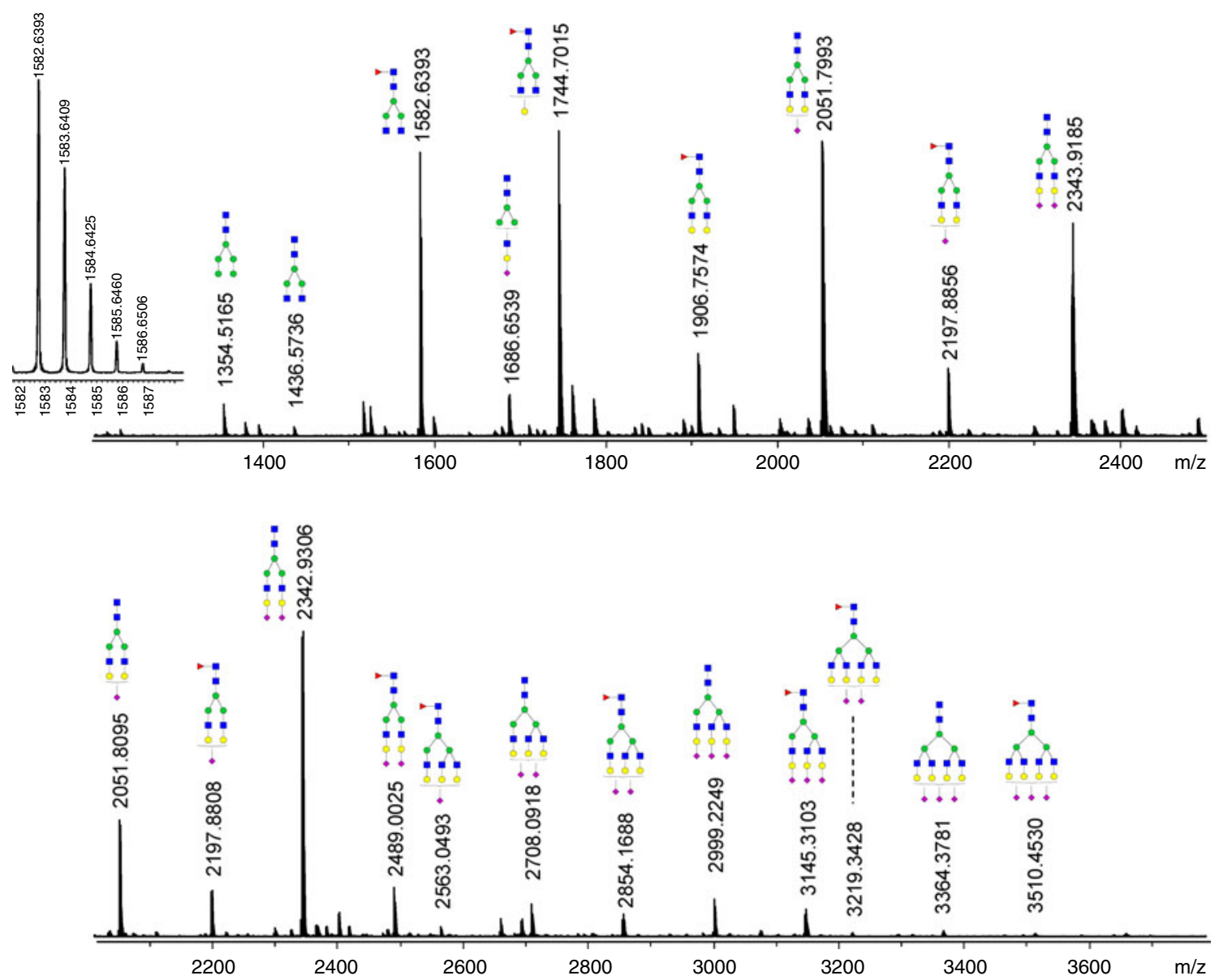

Fig. 8 Analysis of 2-AA-labeled total plasma $N$-glycans by matrixassisted laser desorption/ionization (MALDI)-Fourier transform ion cyclotron resonance (FTICR)-MS. Samples were prepared as described previously [34], desalted by porous graphitized carbon solid-phase extraction, and analyzed by MALDI-FTICR-MS using a 2,5-dihydroxy-

aminobenzoic acid applicable to reductive amination, which are suitable for the direct comparison of four samples which, based on the incorporation of deuterium versus hydrogen atoms, give rise to an isotopic variety with a mass difference of $4 \mathrm{Da}$ between the glycans from different samples. Upon analysis by ESI-quadrupole TOF-MS, the RSDs were below $10 \%$ for compounds with a ratio of more than $1: 3$ between the differentially labeled glycans. These tags are, however, not compatible with LC separation, owing to the large number of deuterium atoms, resulting in retention time shifts.

The previously described labeling techniques are all based on the same principle: introduction of an isotopic tag in vitro. Recently, Orlando et al. [198] reported on the use of an in vivo metabolic isotopic labeling approach using aminosugars containing ${ }^{15} \mathrm{~N}$-glutamine. All GlcNAc, GalNAc, and sialic acids become labeled with ${ }^{15} \mathrm{~N}$, resulting in a mass increase of $1 \mathrm{Da}$. With use of this approach, differentially labeled cell glycans can be mixed prior to all sample preparation procedures, thus reducing the risk of bias due to sample handling. benzoic acid matrix. The low-mass range (top) and the high-mass range (bottom) were measured using different ion-transfer times. The inset shows the isotope pattern of registered glycan species. Yellow circles galactose, green circles mannose, blue squares $N$-acetylglucosamine, purple diamonds sialic acid, red triangles fucose

Isobaric derivatives have the same nominal mass, whereas the accurate mass is different. An example is the derivatization via permethylation using either ${ }^{13} \mathrm{CH}_{3} \mathrm{I}$ or ${ }^{12} \mathrm{CH}_{2} \mathrm{DI}$, resulting in a mass difference $(\Delta m)$ of 0.003 Da per permethylation site as applied. This approach, called "quantification by isobaric labeling", has been described recently for comparative glycomics of both $N$-glycans and $O$-glycans [61, 91] All glycans have multiple methylation sites and, owing to the multiplication of the mass-shift, mass differences for the discrimination of differentially labeled glycan pairs to be analyzed using high-resolution mass spectrometers (e.g., Fourier transform MS) are obtained.

\section{Microarrays}

Although most of the methods discussed in this review deal with glycan labeling and analysis for identification, purification, and structural characterization, this section is dedicated to labeling approaches which combine structural 
characterization with biomolecular interaction analysis. In glycan binding assays using microarrays and microtitration plates, glycans are often immobilized, which may be achieved in a covalent or noncovalent manner. Carbohydrate-binding proteins (CBPs) such as animal or plant lectins and immunoglobulins are then applied. Fluorescence detection of attached CBPs is achieved by either directly labeling the CBPs or using fluorescently labeled secondary antibodies.

For noncovalent immobilization, Liu et al. [200] have established two types of neoglycolipid probes for glycan microarrays: glycans may be conjugated to 1,2-dihexadecyl$s n$-glycero-3-phosphoethanolamine via reductive amination or to aminooxy-functionalized 1,2-dihexadecyl-sn-glycero-3phosphoethanolamine via oxime ligation. Neoglycolipid probes are purified by silica chromatography, structurally characterized by MS, and used for preparing glycan microarrays.

Several biotin-containing tags are available for glycan labeling (see "Reductive amination" and "Hydrazide labeling") offering the possibility to perform microtitration-plate binding assays $[57,58]$ as well as glycan microarray analyses combined with surface plasmon resonance detection [201]. BACH-labeled glycans have recently been shown to be suitable for detailed structural analysis by LC-MS [55], which, together with the aforementioned binding assays, offers the possibility to identify natural ligands of CBPs.
Xia et al. [80] introduced 2,6-diaminopyridine, which carries two aromatic amine groups, as a versatile tag. After reductive amination, the free amine groups can be further coupled to any kind of $N$-hydroxysuccinimide-activated reagent, allowing immobilization on array surfaces or biotin labeling [80]. We have recently shown that glycans isolated from natural sources and labeled with fluorescent tags such as 2-AA and 2-AB using reductive amination are not only suitable for many separation techniques with fluorescence and massspectrometric detection (see "Separation methods"), but can also directly be used for covalent immobilization on a natural glycan microarray [202] (Fig. 9). The key to this approach is the reactivity of epoxy-activated slides which react with the secondary amine group linking the fluorescent tag with the oligosaccharide moiety, thereby allowing the oriented immobilization of fluorescently labeled glycans on microarray slides (Fig. 9d). Microarrays generated in this manner have been probed for interaction with CBPs by both fluorescence detection [202] and surface plasmon resonance [203].

\section{Discussion}

In this section we will discuss some aspects regarding the choice of a glycan label such as the introduction of changes
A. Derivatization<smiles>[R]C([R])C([R])C([R])O</smiles><smiles>NC(=O)c1ccccc1N</smiles><smiles>CCCCC</smiles>
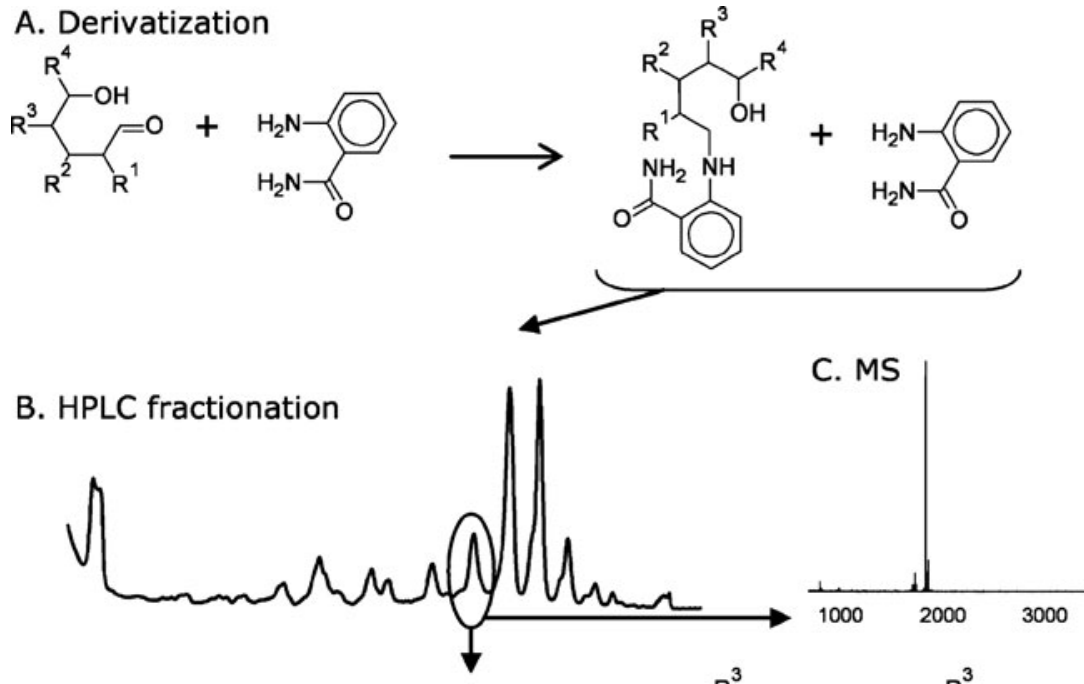

D. Immobilization
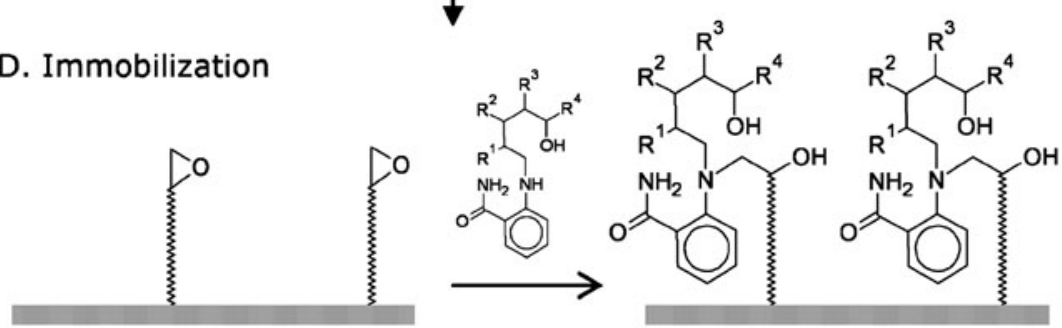

\section{E. Microarray analysis}

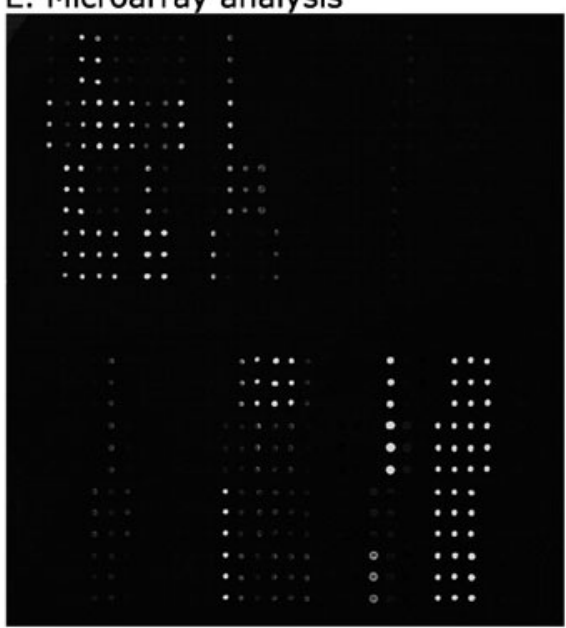

F. Data evaluation

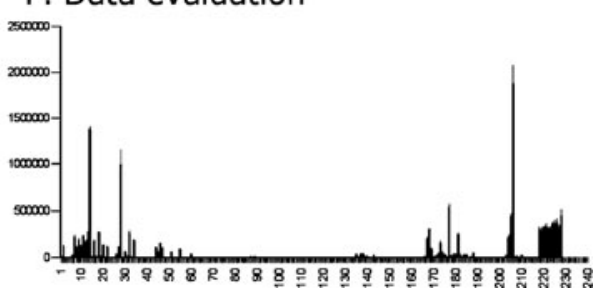

Fig. 9 A natural glycan microarray approach with reductively aminated glycans. a Glycans are derivatized, b fractionated by HPLC, $\mathbf{c}$ analyzed by MALDI time of flight MS(/MS), d immobilized on microarray epoxide slides, $\mathbf{e}$ assayed for protein interaction, and $\mathbf{f}$ the data obtained are interpreted. (Reproduced from [202] with permission) 
in glycan properties upon derivatization, sample preparation, and requirements for the analytical method.

\section{Sample preparation}

Next to detection and separation properties of a specific label, the derivatization process together with possible matrix effects also have to be taken into account when choosing a label. Some labels require optimized reaction conditions as the equilibrium is on the side of the nonlabeled glycans and the free label. This holds true for the common labeling scheme for $2-\mathrm{AB}$, which requires organic solvents as the reaction solution, and for APTS, for which only poor labeling yields may be achieved [75].

Most analytical techniques require a purification step after sample derivatization. MALDI and HPAEC need samples with low amounts of salts, which is also the case for some electromigrative separation techniques. Acetone purification as well as paper chromatography leave the sample with quite some matrix compounds and salts; therefore, SPE methods may be preferred.

The removal of excess label is taken into account in most strategies, as problems with overload, column contamination, or quenching of signals (in MS) can occur. Hydrophilic labels are generally difficult to remove from the glycans, as their properties resemble more closely those of the glycans. An example is APTS, which is difficult to remove using HILIC and RP-SPE. Very hydrophobic labels most likely require easy-to-use RP-SPE; however, they are not compatible with many subsequent separation techniques. In addition, introduction of hydrophobic properties to the glycans can give rise to interferences with proteins and peptides in both purification and separation as these biomolecules usually show a higher hydrophobicity than the glycans. As the mechanism of binding on PGC-SPE is not fully understood, the optimization is dominated by trial and error as the adsorption and the loading capacity cannot easily be judged.

In general, with both PGC-SPE and HILIC-SPE, both labeled and unlabeled glycans are retained and can be analyzed with appropriate analytical techniques. This is not the case in RP-SPE, where the label dominates binding and unlabeled glycans are usually not retained.

In recent years there has been an onset of commercialization of purification strategies. More effort in this field can be expected in the coming years.

\section{Separation methods}

Most applications use separation techniques to gain information on the glycan content and to identify the glycans. Charge and hydrophobicity are major criteria in choosing a particular label. Charge plays a major role in several separation techniques, such as electromigrative separation techniques, anion-exchange chromatography, mixed-mode anion exchange/HILIC separations, and HPAEC. In CE-based separations the charge is necessary to provide the glycan with an effective electrophoretic mobility for migration. Glycan labeling with APTS and ANTS is often applied for CE: with their three sulfonic acid groups, both labels provide a nearly $\mathrm{pH}$ independent high anionic charge, giving rise to low analysis times. Laserinduced-fluorescence detection is applied at 488 and $325 \mathrm{~nm}$, respectively [105, 108, 109, 126, 147]. Good detection limits can also be obtained by mass-spectrometric detection by taking advantage of the highly sensitive and selective negative ionization mode and the high negative charge of the labeled glycans [105]. Good results can also be obtained using 2-AA-labeled glycans with either laserinduced-fluorescence ( 325 or $355 \mathrm{~nm}$ ) or ESI-MS detection in negative ionization mode using CE or CGE (see Table 2).

HPAEC separation of glycans requires a (partial) negative charge, which may be achieved by partial deprotonation of glycan hydroxyl groups at high $\mathrm{pH}$. Under these conditions, a charge-based separation of native glycans as well as glycans derivatized with a neutral label can be achieved. The introduction of labels providing an additional negative charge leads to an increase in retention times, but a change or enhancement in selectivity is not to be expected.

Glycan separation using HILIC is dominated by the physical properties of the glycan moiety. The label often has little influence on the separation. HILIC can be used as an SPE method for the purification of glycans after labeling, as small aromatic molecules such as 2-AA and 2-AB are hardly retained [34]. Notably, the APTS label, which owing to the three sulfonic acid groups has pronounced hydrophilic properties, leads to longer migration times of labeled glycans in HILIC compared with native glycans (unpublished results). In RP-HPLC native glycans are hardly retained, and retention is largely determined by the label. Separation of 2-AB-labeled $N$ glycans has been demonstrated with resolution of structural isomers and detection by (tandem) MS, showing the potential of RP-HPLC [180]. Separation by PGC somehow resembles RP-HPLC, yet with significant retention of native glycans and charge effects contributing to retention.

Summarizing, there are a few labels that are suitable for a large number of different applications. 2-AB, for example, has been shown to be applicable for MALDI, HILIC, RPLC, PGC separation, and HPAEC. It gives rise to reasonable signal intensities in ESI and can be used for fluorescence detection. 2-AA shows a somewhat similar broad applicability; it can, however, also be applied in electromigrative separation techniques as it introduces an anionic charge at intermediate to high $\mathrm{pH}$. Moreover, in contrast to 2-AB, it can be used for MALDI-TOF-MS analysis of both neutral and sialylated glycans in negative ionization mode [34]. 
However, complex mixtures of $\mathrm{N}$-glycans tend to be less efficiently separated by RP-HPLC in 2-AA-labeled form than in 2-AB-labeled form (unpublished observations).

Regarding the determination of labeling yields, those methods which allow the simultaneous separation and detection of nonlabeled and labeled glycans have to be considered. MS-based detection techniques as well as PAD are the few ones available. For separation, HPAEC, PGC and HILIC can be used. CE with mass-spectrometric detection will allow the analysis of sialylated glycans with and without a reducing end label, but not of the nonlabeled neutral glycans.

\section{Optical detection}

Several glycan labels are suitable for UV detection, for example, 2-AA, with an absorption maximum at $214 \mathrm{~nm}$ [204], and PMP, with an absorption maximum at $245 \mathrm{~nm}$ [205]. However, as many other biomolecules likewise absorb UV light, the specificity is generally low, and alternative detection techniques are usually preferred also to achieve better sensitivity. Fluorescence detection is the most commonly used optical detection method for glycan analysis. Whereas lamp-based fluorescence can be applied in chromatographic techniques, $\mathrm{CE}$ usually requires lasers as excitation sources owing to the short optical path length for detection in the capillary. Therefore, fluorescent labels have to be chosen which exhibit excitation/emission properties that match the wavelengths of common lasers, such as the argon laser at $488 \mathrm{~nm}$ (APTS), the $\mathrm{He}-\mathrm{Cd}$ laser at $325 \mathrm{~nm}(2-\mathrm{AA}, 2-\mathrm{AB})$, and the frequency-tripled $\mathrm{Nd}$ : YAG laser at $355 \mathrm{~nm}$ (2-AA, 2-AB) (see also Table 2).

\section{Amperometric detection}

Amperometric detection is almost exclusively used in combination with HPAEC [206]. It enables the analysis of both labeled and unlabeled glycans. However, this detection method is not very selective, and compounds from the sample matrix such as amino acids also give rise to signals. With use of a membrane desalter, capillary-format HPAEC with amperometric detection was successfully combined with online ESI-MS for glycan characterization [207].

Mass-spectrometric detection

Mass-spectrometric detection of glycans by both ESI-MS and MALDI-MS is usually enhanced by glycan labeling compared with the analysis of unlabeled glycans. Both the hydrophobicity and the charge brought in by the label can be advantageous. Some tags are particularly suitable for detection in the positive ionization mode (e.g., PMP, 2-AB); others are preferably used with negative ionization mode (e.g.,
ANTS, APTS). Other labels such as 2-AA have been shown to give rise to acceptable signal intensities in both ionization modes [75]. Tandem MS of glycans as alkali adducts or in deprotonated form by (high-energy) CID is particularly valuable for structural characterization owing to the observed cross-ring cleavages which provide linkage information $[8$, $9,22,192]$. Obviously, extensive cross-ring cleavages often lead to rather complex spectra, making spectral assignment challenging [161, 162].

Sialic acids

The analysis of sialylated glycans is still a challenge. Many researchers decide not to record the degree of sialylation and use neuraminidases to remove the sialic acids from the glycans [38]. This largely simplifies glycan patterns, and at the same time increases the repeatability of the method.

If the determination of sialoforms is of interest, labeling and purification conditions should be chosen that reduce the risk of sialic acid hydrolysis: steps including low $\mathrm{pH}$ and high temperature and especially the combination of both have to be avoided. Users might consider labeling strategies other than acidic reductive amination, e.g., PMP labeling, to reduce the risk of hydrolysis. In addition, the acidic conditions under which storage takes place might catalyze hydrolysis. Loss of sialic acids also occurs when glycans are stored on MALDI plates with DHB as the matrix (unpublished results). Permethylation can largely stabilize sialic acids; however, the choice of the subsequent analytical techniques is then reduced owing to the increase in hydrophobicity of the labeled glycans. Loss of sialic acids during LC or CE separations is usually not a problem, even when very acidic conditions are applied. However, in combination with heating of the separation system, loss of sialic acid might become noticeable.

Detection with MS using ESI or MALDI can likewise give rise to loss of sialic acids by in-source decay or metastable decay. Using a separation method capable of separating sialylated from nonsialylated glycoforms is advantageous, as it allows one to discriminate on the basis of retention/migration times between sialylated glycan species which are present in the sample and those species which are formed by desialylation during MS.

Quantification and profiling

Relative quantification of labeled glycans by massspectrometric analysis has been shown to yield consistent results [34, 193]. One important aspect to take into consideration is the occurrence of in-source decay, where mainly sialic acids are lost, but also the loss of full antennae can be observed. The use of specific ion sources such as intermediate-pressure MALDI may successfully minimize 
in-source decay [185], whereas sialic acids may also be stabilized using permethylation [22].

In MALDI, DHB is widely used as the matrix. DHB usually results in macrocrystalline sample preparations. Recrystallization using ethanol leads to smaller, more equally distributed crystals, which enhances shot-to-shot reproducibility and is therefore advantageous for quantification, also in combination with automatic measurements.

Next to relative quantitation, absolute quantitation with internal standards is possible for comparative glycomics. For this purpose, stable isotope labels may be used in combination with MS (see "Comparative glycomics by MS"). The use of isotope-labeled PA or 2-AA may be easy to implement in laboratories where the nonisotopic derivatives are already in use $[40,41]$. Unfortunately, deuterium may result in retention shifts in chromatography, and $\Delta m$ between glycan pairs for these labels is only $4 \mathrm{Da}$. Both disadvantages may be overcome by the use of aniline, which is labeled by ${ }^{13} \mathrm{C}$, and generates $\Delta m$ of 6 Da $[43,44]$. Aniline derivatives cannot be detected on the basis of fluorescence, but only by UV detection. However, as absolute quantitation using isotope-labeled internal standards will rely on mass-spectrometric detection, the lack of fluorescence detection should not represent a major drawback.

As an alternative, glycans may be isotope-labeled by permethylation $[70,71,196]$. Again, this will be easy in laboratories where permethylation is already employed; however, since the number of permethylation sites may differ per glycan, the $\Delta m$ generated is also different per glycan. When this method is applied to compare complex mixtures, it will result in rather complex mass spectra. Recently an attempt to implement four-plex isotope labeling has been published [197]. Unfortunately, mass shifts are generated by the introduction of deuterium, which makes the use of chromatography difficult. Moreover, the labels are not commercially available yet.

As a counterpart to the stable isotope labelling by amino acids in cell culture method, which is widely applied in proteomics, ${ }^{15} \mathrm{~N}$ metabolic labeling of oligosaccharides via glutamate may be employed [198]. Since only 1 Da mass difference is generated per GlcNAc, GalNAc, and sialic acid residue, the overall $\Delta m$ per glycan is often quite small. Moreover, this method may be applied in cell cultures, but is not suitable for the comparison of patient material.

The use of isobaric labeling has only very recently been introduced to glycomics $[61,91]$. With use of this approach, pairs of labeled glycans are detected at the same nominal mass. As only very small mass differences are generated, the use of high-resolution MS, which is not available in every laboratory, is necessary.

All of these methods have not been used in larger sample sets yet, and we expect further labels to be developed, as well as commercialization of such tags.
Acknowledgements L.R.R. was supported by IOP Grant IGE05007, G.Z. by the Netherlands Genomics Initiative (Horizon Breakthrough Project 93518016), and C.H. by a fellowship within the PostdocProgram of the German Academic Exchange Service (DAAD).

Open Access This article is distributed under the terms of the Creative Commons Attribution Noncommercial License which permits any noncommercial use, distribution, and reproduction in any medium, provided the original author(s) and source are credited.

\section{References}

1. Parekh R, Roitt I, Isenberg D, Dwek R, Rademacher T (1988) J Exp Med 167:1731-1736

2. Parekh RB, Dwek RA, Sutton BJ, Fernandes DL, Leung A, Stanworth D, Rademacher TW, Mizuochi T, Taniguchi T, Matsuta K (1985) Nature 316:452-457

3. Peracaula R, Tabares G, Royle L, Harvey DJ, Dwek RA, Rudd PM, De Llorens R (2003) Glycobiology 13:457-470

4. Saldova R, Royle L, Radcliffe CM, Abd Hamid UM, Evans R, Arnold JN, Banks RE, Hutson R, Harvey DJ, Antrobus R, Petrescu SM, Dwek RA, Rudd PM (2007) Glycobiology $17: 1344-1356$

5. Jefferis R (2005) Biotechnol Prog 21:11-16

6. Shibata-Koyama M, Iida S, Misaka H, Mori K, Yano K, Shitara K, Satoh M (2009) Exp Hematol 37:309-321

7. Geyer H, Geyer R (2006) Biochim Biophys Acta 1764:1853-1869

8. Zaia J (2004) Mass Spectrom Rev 23:161-227

9. Mechref Y, Novotny MV (2002) Chem Rev 102:321-369

10. Huhn C, Selman MH, Ruhaak LR, Deelder AM, Wuhrer M (2009) Proteomics 9:882-913

11. Yamamoto K (1994) J Biochem 116:229-235

12. Hanisch FG, Jovanovic M, Peter-Katalinic J (2001) Anal Biochem 290:47-59

13. Chai W, Feizi T, Yuen CT, Lawson AM (1997) Glycobiology 7:861-872

14. Huang Y, Mechref Y, Novotny MV (2001) Anal Chem 73:60636069

15. Huang Y, Konse T, Mechref Y, Novotny MV (2002) Rapid Commun Mass Spectrom 16:1199-1204

16. Gerken TA, Gupta R, Jentoft N (1992) Biochemistry 31:639-648

17. Zheng Y, Guo Z, Cai Z (2009) Talanta 78:358-363

18. Harvey DJ (2003) Int J Mass Spectrom 226:1-35

19. Merry AH, Neville DC, Royle L, Matthews B, Harvey DJ, Dwek RA, Rudd PM (2002) Anal Biochem 304:91-99

20. Nakakita S, Sumiyoshi W, Miyanishi N, Hirabayashi J (2007) Biochem Biophys Res Commun 362:639-645

21. Manzi AE, Norgard-Sumnicht K, Argade S, Marth JD, van Halbeek H, Varki A (2000) Glycobiology 10:669-689

22. Morelle W, Michalski JC (2007) Nat Protoc 2:1585-1602

23. Royle L, Mattu TS, Hart E, Langridge JI, Merry AH, Murphy N, Harvey DJ, Dwek RA, Rudd PM (2002) Anal Biochem 304:70-90

24. Bigge JC, Patel TP, Bruce JA, Goulding PN, Charles SM, Parekh RB (1995) Anal Biochem 230:229-238

25. Evangelista RA, Guttman A, Chen FT (1996) Electrophoresis $17: 347-351$

26. Anumula KR (1994) Anal Biochem 220:275-283

27. Anumula KR (2006) Anal Biochem 350:1-23

28. Shilova NV, Bovin NV (2003) Russ J Bioorgan Chem 29:309-324

29. Royle L, Campbell MP, Radcliffe CM, White DM, Harvey DJ, Abrahams JL, Kim YG, Henry GW, Shadick NA, Weinblatt ME, Lee DM, Rudd PM, Dwek RA (2008) Anal Biochem 376:1-12

30. Deguchi K, Keira T, Yamada K, Ito H, Takegawa Y, Nakagawa H, Nishimura S (2008) J Chromatogr A 1189:169-174 
31. Takegawa $\mathrm{Y}$, Deguchi $\mathrm{K}$, Ito $\mathrm{H}$, Keira $\mathrm{T}$, Nakagawa $\mathrm{H}$, Nishimura S (2006) J Sep Sci 29:2533-2540

32. Takahashi N, Yagi H, Kato K (2008) In: Taniguchi N, Suzuki A, Ito $\mathrm{H}$, Narimatsu H, Kawasaki T, Hase S (eds) Experimental dlycoscience. Springer, Tokyo, pp 7-11

33. Anumula KR, Dhume ST (1998) Glycobiology 8:685-694

34. Ruhaak LR, Huhn C, Waterreus WJ, de Boer AR, Neususs C, Hokke CH, Deelder AM, Wuhrer M (2008) Anal Chem 80:6119-6126

35. Yu YQ, Gilar M, Kaska J, Gebler JC (2005) Rapid Commun Mass Spectrom 19:2331-2336

36. Kamoda S, Ishikawa R, Kakehi K (2006) J Chromatogr A 1133:332-339

37. Callewaert N, Geysens S, Molemans F, Contreras R (2001) Glycobiology 11:275-281

38. Laroy W, Contreras R, Callewaert N (2006) Nat Protoc 1:397-405

39. Suzuki H, Muller O, Guttman A, Karger BL (1997) Anal Chem 69:4554-4559

40. Yuan J, Hashii N, Kawasaki N, Itoh S, Kawanishi T, Hayakawa T (2005) J Chromatogr A 1067:145-152

41. Hitchcock AM, Yates KE, Costello CE, Zaia J (2008) Proteomics 8:1384-1397

42. Hitchcock AM, Costello CE, Zaia J (2006) Biochemistry 45:2350-2361

43. Xia B, Feasley CL, Sachdev GP, Smith DF, Cummings RD (2009) Anal Biochem 387:162-170

44. Ridlova G, Mortimer JC, Maslen SL, Dupree P, Stephens E (2008) Rapid Commun Mass Spectrom 22:2723-2730

45. Dalpathado DS, Jiang H, Kater MA, Desaire H (2005) Anal Bioanal Chem 381:1130-1137

46. Locke D, Bevans CG, Wang LX, Zhang Y, Harris AL, Lee YC (2004) Carbohydr Res 339:221-231

47. Ruhaak LR, Steenvoorden E, Koeleman CAM, Deelder AM, Wuhrer M (2009) submitted

48. Evangelista RA, Chen FT, Guttman A (2006) J Chromatogr A $745: 273-280$

49. Chen FT, Dobashi TS, Evangelista RA (1998) Glycobiology 8:1045-1052

50. You J, Sheng X, Ding C, Sun Z, Suo Y, Wang H, Li Y (2008) Anal Chim Acta 609:66-75

51. Fu D, O’Neill RA (1995) Anal Biochem 227:377-384

52. Yang X, Zhao Y, Ruan Y, Yang Y (2008) Biol Pharm Bull 31:1860-1865

53. Kakehi K, Ueda M, Suzuki S, Honda S (1993) J Chromatogr 630:141-146

54. Lattova E, Perreault H (2003) J Chromatogr B 793:167-179

55. Kapkova P (2009) Rapid Commun Mass Spectrom 23:27752784

56. Leteux C, Childs RA, Chai W, Stoll MS, Kogelberg H, Feizi T (1998) Glycobiology 8:227-236

57. Leteux C, Stoll MS, Childs RA, Chai W, Vorozhaikina M, Feizi T (1999) J Immunol Methods 227:109-119

58. Shinohara Y, Sota H, Gotoh M, Hasebe M, Tosu M, Nakao J, Hasegawa Y, Shiga M (1996) Anal Chem 68:2573-2579

59. Grun CH, van Vliet SJ, Schiphorst WE, Bank CM, Meyer S, van Die I, van Kooyk Y (2006) Anal Biochem 354:54-63

60. Gil GC, Kim YG, Kim BG (2008) Anal Biochem 379:45-59

61. Botelho JC, Atwood JA, Cheng L, Varez-Manilla G, York WS, Orlando R (2008) Int J Mass Spectrom 278:137-142

62. Guillard M, Gloerich J, Wessels HJ, Morava E, Wevers RA, Lefeber DJ (2009) Carbohydr Res 344:1550-1557

63. Prien JM, Ashline DJ, Lapadula AJ, Zhang H, Reinhold VN (2009) J Am Soc Mass Spectrom 20:539-556

64. Kerek CI, Ciucanu I (1984) Carbohydr Res 131:209-217

65. Robinson S, Bergstrom E, Seymour M, Thomas-Oates J (2007) Anal Chem 79:2437-2445
66. Costello CE, Contado-Miller JM, Cipollo JF (2007) J Am Soc Mass Spectrom 18:1799-1812

67. Dell A (1990) Methods Enzymol 193:647-660

68. Easton RL, Patankar MS, Clark GF, Morris HR, Dell A (2000) J Biol Chem 275:21928-21938

69. Kang P, Mechref Y, Klouckova I, Novotny MV (2005) Rapid Commun Mass Spectrom 19:3421-3428

70. Kang P, Mechref Y, Kyselova Z, Goetz JA, Novotny MV (2007) Anal Chem 79:6064-6073

71. Kang P, Mechref Y, Novotny MV (2008) Rapid Commun Mass Spectrom 22:721-734

72. Lei M, Mechref Y, Novotny MV (2009) J Am Soc Mass Spectrom 20:1660-1671

73. Wheeler SF, Domann P, Harvey DJ (2009) Rapid Commun Mass Spectrom 23:303-312

74. Anumula KR (2000) Anal Biochem 283:17-26

75. Pabst M, Kolarich D, Poltl G, Dalik T, Lubec G, Hofinger A, Altmann F (2009) Anal Biochem 384:263-273

76. Nakagawa H, Hato M, Takegawa Y, Deguchi K, Ito H, Takahata M, Iwasaki N, Minami A, Nishimura S (2007) J Chromatogr B 853:133-137

77. Vanderschaeghe D, Debruyne E, Van Vlierberghe H, Callewaert N, Delanghe J (2009) Electrophoresis 30:1-7

78. Saba JA, Shen X, Jamieson JC, Perreault H (2001) J Mass Spectrom 36:563-574

79. Morelle W, Page A, Michalski JC (2005) Rapid Commun Mass Spectrom 19:1145-1158

80. Xia B, Kawar ZS, Ju T, Alvarez RA, Sachdev GP, Cummings RD (2005) Nat Methods 2:845-850

81. Packer NH, Lawson MA, Jardine DR, Redmond JW (1998) Glycoconj J 15:737-747

82. Broberg A (2007) Carbohydr Res 342:1462-1469

83. Wuhrer M, Koeleman CAM, Deelder AM, Hokke CH (2006) FEBS J 273:347-361

84. Ruhaak LR, Deelder AM, Wuhrer M (2009) Anal Bioanal Chem 394:163-174

85. Geyer R, Geyer H (1994) Methods Enzymol 230:86-107

86. Prater BD, Anumula KR, Hutchins JT (2007) Anal Biochem 369:202-209

87. Olajos M, Hajos P, Bonn GK, Guttman A (2008) Anal Chem 80:4241-4246

88. Schwarzer J, Rapp E, Reichl U (2008) Electrophoresis 29:42034214

89. Yamaguchi Y, Nishimura M, Nagano M, Yagi H, Sasakawa H, Uchida K, Shitara K, Kato K (2006) Biochim Biophys Acta 1760:693-700

90. Kita Y, Miura Y, Furukawa J, Nakano M, Shinohara Y, Ohno M, Takimoto A, Nishimura S (2007) Mol Cell Proteomics 6:1437-1445

91. Atwood JA III, Cheng L, Varez-Manilla G, Warren NL, York WS, Orlando R (2008) J Proteome Res 7:367-374

92. Royle L, Radcliffe CM, Dwek RA, Rudd PM (2006) Methods Mol Biol 347:125-143

93. Takahashi N (1996) J Chromatogr A 720:217-225

94. Amon S, Zamfir AD, Rizzi A (2008) Electrophoresis 29:2485-2507

95. El Rassi Z, Mechref Y (1996) Electrophoresis 17:275-301

96. El Rassi Z (1997) Electrophoresis 18:2400-2407

97. Kamoda S, Kakehi K (2006) Electrophoresis 27:2495-2504

98. Tran NT, Taverna M, Deschamps FS, Morin P, Ferrier D (1998) Electrophoresis 19:2630-2638

99. Zamfir A, Peter-Katalinic J (2004) Electrophoresis 25:1949-1963 100. Raju TS (2000) Anal Biochem 283:1225-132

101. Mechref Y, Novotny MV (2009) Mass Spectrom Rev 28:207-222

102. Scheinthal BM, Bettelheim FA (1968) Carbohydr Res 6:257-265

103. Zhuang Z, Starkey JA, Mechref Y, Novotny MV, Jacobson SC (2007) Anal Chem 79:7170-7175

104. Balaguer E, Neusüß C (2006) Anal Chem 78:5384-5393 
105. Gennaro LA, Salas-Solano O (2008) Anal Chem 80:3838-3845 106. Fang H, Kaur G, Wang B (2004) J Fluoresc 14:481-489

107. Kitahara K, Noguchi Y, Itoh S, Chiba N, Tohyama T, Nagashima K, Hanada T, Yoshihama I, Arai S (2009) J Chromatogr A 1216:7415-7421

108. Chen F-TA, Evangelista RA (1998) Electrophoresis 19:2639-2644

109. Kamoda S, Nomura C, Kinoshita M, Nishuira S, Ishikawa R, Kakehi K, Kawasaki N, Hayakawa T (2004) J Chromatogr A 1050:211-216

110. Kamoda S, Nakanishi Y, Kinoshita M, Ishikawa R, Kakehi K (2006) J Chromatogr A 1106:67-74

111. Guryca V, Mechref Y, Palm AK, Michálek J, Pacákova V, Novotný MV (2007) J Biochem Biophys Methods 70:3-13

112. Liu C-Y, Chen T-H, Misra TK (2007) J Chromatogr A 1154:407415

113. Que AH, Novotny MV (2002) Anal Chem 74:5184-5191

114. Que AH, Novotny MV (2003) Anal Chem 375:599-608

115. Suzuki S, Honda S (2001) Chromatography 22:171-179

116. Zhong H, El Rassi Z (2009) J Sep Sci 32:10-20

117. Que AH, Mechref Y, Hunag Y, Taraszka JA, Clemmer DE, Novotny MV (2003) Anal Chem 75:1684-1690

118. Plocek J, Chmelík J (1997) Electrophoresis 18:1148-1152

119. Garner TW, Yeung ES (1990) J Chromatogr 515:639-644

120. Klockow A, Paulus A, Figueiredo V, Amadò R, Widmer HM (2009) J Chromatogr A 680:187-200

121. Vorndran AE, Oefner PJ, Scherz H, Bonn GK (1992) Chromatographia 33:163-168

122. Klampfl CW, Buchberger W (2001) Electrophoresis 22:2737-2742

123. Colón LA, Dadoo R, Zare RN (1993) Anal Chem 65:476-481

124. Hoffstetter-Kuhn S, Paulus A, Gassmann E, Widmer HM (1991) Anal Chem 63:1541-1547

125. Hughes DE (1994) J Chromatogr B 657:315-326

126. Evangelista RA, Li M-S, Chen F-TA (1995) Anal Chem 67:2239-2245

127. Camilleri P, Harland GB, Okafo G (1995) Anal Biochem 230:115-122

128. Okafo G, Burrow LM, Carr SA, Roberts GD, Johnson W, Camilleri P (1996) Anal Chem 68:4424-4430

129. Okafo GN, Burrow LM, Neville W, Truneh A, Smith RAG, Reff M, Camilleri P (1996) Anal Biochem 240:68-74

130. Nakano M, Higo D, Arai E, Nakagawa T, Kakehi K, Taniguchi N, Kondo A (2009) Glycobiology 19:135-143

131. Nashabeh W, El Rassi Z (1992) J Chromatogr 600:279-287

132. Rydlund A, Dahlman O (1996) J Chromatogr A 738:129-140

133. Perez SA, Colón LA (1996) Electrophoresis 17:352-358

134. Lin Q, Zhang R, Liu G (1997) J Liq Chromatogr Relat Technol 20:1123-1137

135. Ma S, Nashabeh W (1999) Anal Chem 71:5158-5192

136. Guttman A, Cooke N, Star CM (1994) Electrophoresis 15:15181522

137. Guttman A, Pritchett T (1995) Electrophoresis 16:1906-1911

138. Guttman A (1997) Electrophoresis 18:1136-1141

139. Guttman A, Chen F-TA, Evangelista RA (1996) Electrophoresis $17: 412-417$

140. Matsuno YK, Yamada K, Tanabe A, Kinoshita M, Maruyama SZ, Osaka YS, Masuko T, Kakehi K (2007) Anal Biochem 362:245-257

141. Matsuno YK, Nakamura H, Kakehi K (2006) Electrophoresis 27:2486-2494

142. Calabro A, Benavides M, Tammi M, Hascall VC, Midura RJ (2000) Glycobiology 10:273-281

143. Oonuki Y, Yoshida Y, Uchiyama Y, Asari A (2005) Anal Biochem 343:212-222

144. Chiesa C, O’Neill RA (1994) Electrophoresis 15:1132-1140

145. Sandra K, Van Beeumen J, Stals I, Sandra P, Claeyssens M, Devreese B (2004) Anal Chem 76:5878-5886
146. Che F-Y, Song J-F, Zeng R, Wang K-Y, Xia Q-C (1999) J Chromatogr A 858:229-238

147. Klockow A, Amadò R, Widmer HM, Paulus A (1995) J Chromatogr A 716:241-257

148. Endo T, Wright A, Morrison SL, Kobata A (1995) Mol Immunol 32:931-940

149. Kamerling JP, Gerwig GJ, Vliegenthart JF, Clamp JR (1975) Biochem J 151:491-495

150. Gal AE (1968) J Chromatogr 34:266-268

151. Nyame K, Smith DF, Damian RT, Cummings RD (1989) J Biol Chem 264:3235-3243

152. Wuhrer M, de Boer AR, Deelder AM (2009) Mass Spectrom Rev 28:192-206

153. Alpert AJ, Shukla M, Shukla AK, Zieske LR, Yuen SW, Ferguson MA, Mehlert A, Pauly M, Orlando R (1994) J Chromatogr A 676:191-202

154. Hemström P, Irgum K (2006) J Sep Sci 29:1784-1821

155. Tolstikov VV, Fiehn O (2002) Anal Biochem 301:298-307

156. Lochnit G, Geyer R (1995) Eur J Biochem 228:805-816

157. Clarke A, Harmon B, DeFelippis MR (2009) Anal Biochem 390:209-211

158. Thomsson KA, Karlsson NG, Hansson GC (1999) J Chromatogr A 854:131-139

159. Wuhrer M, Koeleman CAM, Hokke CH, Deelder AM (2004) Int J Mass Spectrom 232:51-57

160. Wuhrer M, Koeleman CAM, Deelder AM, Hokke CH (2004) Anal Chem 76:833-838

161. Maslen S, Sadowski P, Adam A, Lilley K, Stephens E (2006) Anal Chem 78:8491-8498

162. Maslen SL, Goubet F, Adam A, Dupree P, Stephens E (2007) Carbohydr Res 342:724-735

163. Campbell MP, Royle L, Radcliffe CM, Dwek RA, Rudd PM (2008) Bioinformatics 24:1214-1216

164. Knezevic A, Polasek O, Gornik O, Rudan I, Campbell H, Hayward C, Wright A, Kolcic I, O’Donoghue N, Bones J, Rudd PM, Lauc G (2009) J Proteome Res 8:694-701

165. Staples GO, Bowman MJ, Costello CE, Hitchcock AM, Lau JM, Leymarie N, Miller C, Naimy H, Shi X, Zaia J (2009) Proteomics 9:686-695

166. Neville DC, Dwek RA, Butters TD (2009) J Proteome Res 8:681-687

167. Zamze S, Harvey DJ, Chen YJ, Guile GR, Dwek RA, Wing DR (1998) Eur J Biochem 258:243-270

168. Kotani N, Takasaki S (1998) Anal Biochem 264:66-73

169. Ridley BL, Spiro MD, Glushka J, Albersheim P, Darvill A, Mohnen D (1997) Anal Biochem 249:10-19

170. Stubbs HJ, Shia MA, Rice KG (1997) Anal Biochem 247:357365

171. Collard WT, El Halaby JM, Rice KG (1997) Anal Biochem 247:448-450

172. Karlsson NG, Schulz BL, Packer NH (2004) J Am Soc Mass Spectrom 15:659-672

173. Wilson NL, Robinson LJ, Donnet A, Bovetto L, Packer NH, Karlsson NG (2008) J Proteome Res 7:3687-3696

174. Pabst M, Altmann F (2008) Anal Chem 80:7534-7542

175. Pabst M, Bondili JS, Stadlmann J, Mach L, Altmann F (2007) Anal Chem 79:5051-5057

176. Stadlmann J, Pabst M, Kolarich D, Kunert R, Altmann F (2008) Proteomics 8:2858-2871

177. Wuhrer M, Deelder AM, Hokke CH (2005) J Chromatogr B 825:124-133

178. Yamada E, Tsukamoto Y, Sasaki R, Yagyu K, Takahashi N (1997) Glycoconj J 14:401-405

179. Chen X, Flynn GC (2007) Anal Biochem 370:147-161

180. Chen X, Flynn GC (2009) J Am Soc Mass Spectrom 20:18211833 
181. Lattova E, Perreault H (2009) Methods Mol Biol 534:65-77

182. Lattova E, Perreault H (2003) J Chromatogr A 1016:71-87

183. Wuhrer M, Koeleman CA, Deelder AM (2009) Methods Mol Biol 534:79-91

184. Hanisch FG, Muller S (2009) Methods Mol Biol 534:107-115

185. Heiskanen A, Hirvonen T, Salo H, Impola U, Olonen A, Laitinen A, Tiitinen S, Natunen S, Aitio O, Miller-Podraza H, Wuhrer M, Deelder AM, Natunen J, Laine J, Lehenkari P, Saarinen J, Satomaa T, Valmu L (2009) Glycoconj J 26:367-384

186. Harvey DJ (2000) J Mass Spectrom 35:1178-1190

187. Pfenninger A, Karas M, Finke B, Stahl B (2002) J Am Soc Mass Spectrom 13:1331-1340

188. Pfenninger A, Karas M, Finke B, Stahl B (2002) J Am Soc Mass Spectrom 13:1341-1348

189. Harvey DJ (2005) J Am Soc Mass Spectrom 16:647-659

190. Harvey DJ (2005) J Am Soc Mass Spectrom 16:631-646

191. Harvey DJ (2005) J Am Soc Mass Spectrom 16:622-630

192. Wuhrer M, Deelder AM (2005) Anal Chem 77:6954-6959

193. Wada Y, Azadi P, Costello CE, Dell A, Dwek RA, Geyer H, Geyer R, Kakehi K, Karlsson NG, Kato K, Kawasaki N, Khoo KH, Kim S, Kondo A, Lattova E, Mechref Y, Miyoshi E, Nakamura K, Narimatsu H, Novotny MV, Packer NH, Perreault H, Peter-Katalinic J, Pohlentz G, Reinhold VN, Rudd PM, Suzuki A, Taniguchi N (2007) Glycobiology 17:411-422

194. Hsu NY, Yang WB, Wong CH, Lee YC, Lee RT, Wang YS, Chen CH (2007) Rapid Commun Mass Spectrom 21:2137-2146

195. Bantscheff M, Schirle M, Sweetman G, Rick J, Kuster B (2007) Anal Bioanal Chem 389:1017-1031
196. Alvarez-Manilla G, Warren NL, Abney T, Atwood J III, Azadi P, York WS, Pierce M, Orlando R (2007) Glycobiology 17:677-687

197. Bowman MJ, Zaia J (2007) Anal Chem 79:5777-5784

198. Orlando R, Lim JM, Atwood JA III, Angel PM, Fang M, Aoki K, Alvarez-Manilla G, Moremen KW, York WS, Tiemeyer M, Pierce M, Dalton S, Wells L (2009) J Proteome Res 8:38163823

199. Kline KG, Finney GL, Wu CC (2009) Brief Funct Genomics Proteomics 8:114-125

200. Liu Y, Feizi T, Campanero-Rhodes MA, Childs RA, Zhang Y, Mulloy B, Evans PG, Osborn HM, Otto D, Crocker PR, Chai W (2007) Chem Biol 14:847-859

201. Karamanska R, Clarke J, Blixt O, Macrae JI, Zhang JQ, Crocker PR, Laurent N, Wright A, Flitsch SL, Russell DA, Field RA (2008) Glycoconj J 25:69-74

202. de Boer AR, Hokke CH, Deelder AM, Wuhrer M (2007) Anal Chem 79:8107-8113

203. de Boer AR, Hokke CH, Deelder AM, Wuhrer M (2008) Glycoconj J 25:75-84

204. Rustighi I, Campa C, Rossi M, Semeraro S, Vetere A, Gamini A (2009) Electrophoresis 30:2632-2639

205. Kodama S, Aizawa S, Taga A, Yamashita T, Yamamoto A (2006) Electrophoresis 27:4730-4734

206. Stadheim TA, Li H, Kett W, Burnina IN, Gerngross TU (2008) Nat Protoc 3:1026-1031

207. Bruggink C, Wuhrer M, Koeleman CA, Barreto V, Liu Y, Pohl C, Ingendoh A, Hokke CH, Deelder AM (2005) J Chromatogr B 829:136-143 